\title{
Design, implementation and validation of a Europe-wide pedagogical framework for e-Learning
}

\author{
Andrina Granić ${ }^{\mathrm{a}, *}$, Charles Mifsud ${ }^{\mathrm{b}}$, Maja Ćukušić ${ }^{\mathrm{c}}$ \\ ${ }^{a}$ Faculty of Science, Nikole Tesle 12, Split 21000, Croatia \\ ${ }^{\text {b } C e n t r e ~ f o r ~ L i t e r a c y, ~ U n i v e r s i t y ~ o f ~ M a l t a, ~ M s i d a ~ M S D ~ 06, ~ M a l t a ~}$ \\ ${ }^{\mathrm{c}}$ Faculty of Economics, Matice hrvatske 31, Split 21000, Croatia
}

\section{A R T I C L E I N F O}

\section{Article history:}

Received 16 December 2008

Received in revised form 12 May 2009

Accepted 13 May 2009

\section{Keywords:}

Cross-cultural projects

Interactive learning environments

Pedagogical issues

Secondary education

Teaching/learning strategies

\begin{abstract}
A B S T R A C T
Within the context of a Europe-wide project UNITE, a number of European partners set out to design, implement and validate a pedagogical framework (PF) for e- and m-Learning in secondary schools. The process of formulating and testing the PF was an evolutionary one that reflected the experiences and skills of the various European partners and secondary schools involved in the project. The framework involved pedagogies which underpin the teaching of subject matter in a number of European secondary schools as well as the ways in which learning is delivered and assessed. The PF represents an essential part of the e-Learning system conceptualization and development and offers sound concepts for the development of learning scenarios in order to enhance the learning experience of students in secondary schools. A five-component framework which, by means of its constituents, drives and guides the creation of e-Learning scenarios was designed and tested. It is composed of the pedagogical framework context, pedagogical approaches, assessment techniques, teacher education and national specifics and current pedagogical practices implemented in national curricula. A series of learning scenarios were created to test the PF in classrooms. A detailed exemplar of a scenario in practice is offered. An evaluation of the scenarios based on [Reeves, T. C., 1994. Evaluating what really matters in computer-based education. In M. Wild, D. Kirkpatrick (Eds.), Computer education: new perspectives (pp. 219-246). Perth, Australia: MASTEC] pedagogical dimensions revealed that UNITE is based on constructivist and cognitive foundations. With increased experience of the system the teachers' implementation of the pedagogical framework developed into increased mastery in the school context. Teachers from the second validation phase became more confident in their application of the framework principles and evaluated more positively the outcomes. This helped them to become more aware of the opportunities offered by the framework in their secondary school teaching. In order to bring this about the supports for change were put into place at the levels of pedagogical design, administrative support and the provision of the required resources and appropriate continuing professional development. The project has sought to create this support structure to ensure maximal benefits of the system for teaching and learning. Such a pedagogical support PF has offered scope for both collaborative and autonomous learning which have brought about value-added teaching and learning effects in the Europe-wide network of schools.
\end{abstract}

(c) 2009 Elsevier Ltd. All rights reserved.

\section{Introduction}

When compared to the impact it has had on other sectors of society, the advent of information and communication technology (ICT) has not changed dramatically how teachers teach and how students learn in schools (Downes et al., 2001; Meredyth, Russell, Blackwood, Thomas, \& Wise, 1999). The reasons for the lack of integration of e-Learning into school curricula are a complex mix of the level of access to ICT, teacher motivation and the relationship between pedagogy and the available technologies. The project reported on in this paper has sought to address these reasons and by integrating e-Learning into a number of European school systems.

When designing e-Learning systems it is important to have a clear understanding of the planned pedagogical objectives as well as to decide on which pedagogical approach is to be employed. A framework which we present in the paper covers theories and practices for the enhancement of the learning experience through the use of ICT, and is a good example of e-Learning system design which benefits from

\footnotetext{
* Corresponding author. Tel.: +38521385 133; fax: +38521384086.

E-mail address: andrina.granic@pmfst.hr (A. Granić).
} 
a framework-oriented approach. From a pedagogical point of view, an easy to use e-Learning system is not necessarily also "properly designed". An e-Learning system design based on selected pedagogical model enables teachers to make use of the learning resources in a form which is appropriate to the learning goals and the particular learning style of the student (Granić \& Cukušić, 2007a). All this was borne in mind when designing the UNITE system.

UNITE (unified e-Learning environment for the school) was a 30-month project, partially supported by the European Community under the information society technologies (IST) priority of the sixth Framework Programme for R\&D (UNITE FP6 IST project, 2006). The main objective of the project was to provide innovative approaches to the education of young Europeans by integrating into the curricula of a number of schools in Europe-wide network different state-of-the-art technologies in e-Learning, also taking into consideration innovation in technology and pedagogy. The project was successfully completed in July 2008.

This paper presents the results of a comprehensive theoretical and empirical study related to the design, implementation and validation of a pedagogical framework (PF) which was developed within the context of the project. Pedagogical framework was intended to (i) allow for the use of an e-Learning platform in day-to-day learning and teaching, (ii) offer sound concepts for the development of learning scenarios and (iii) improve the learning experience of students in 14 European schools. As noted earlier the pedagogical framework cover theories and practices for the enhancement of a learning experience. This five-component pedagogical framework, by means of its constituents, produces the set of parameters that drive and guide the creation of e-Learning scenarios. The PF components are: pedagogical framework context, pedagogical approaches, assessment techniques, teacher training and current pedagogical practices implemented in national curricula and national specifics.

The pedagogical framework design results from the first phase (carried out from May to October 2006) in addition to the results of the implementation period from the second phase (conducted from November 2006 to January 2008) are elaborated here along with the validation results from the third phase (February 2008-July 2008). Table 1 lists the schools and related partner institutions participating in the design, implementation and/or validation of the PF. The two institutions participating in the project but not directly involved in school and PF related activities are Fraunhofer Institute for Computer Graphics in Germany, the project coordinator, and Extreme Media Solutions Ltd. in Greece, one of the technical partners. A total of 783 students with an average age of 15.7 years, were involved in the UNITE project.

The paper is structured as follows. Section 2 brings background to the research, particularly addressing background work to the pedagogical framework design. Section 3 introduces the pedagogy-driven approach for embedding ICT in learning and teaching in the context of a Europe-wide project UNITE. The Section elaborates on the fundamental components of the designed five-dimensional framework as well. Section 4 presents the framework application instruments and provides an insight into the implementation of the framework in the network of fourteen European schools. Section 5 brings the results of the validation phase. Section 6 offers summary and discussion, while Section 7 concludes the paper.

\section{Background to the research}

With the introduction of computers in classroom settings there was the exuberant hope that technology would bring about the same kind of successful transformation that had been seen in science, industry and business where its role seems to be obvious. However, the role of technology in education is not so obvious. This is in part due to the fact that the process and product of formal education remain largely unspecified. Perspectives on learning change constantly and images of teaching vary widely (Greene, 1979). Learning outcomes are equally debatable. Furthermore children bring to schools many individual differences. It has been claimed that “... .although technology is often touted as the great salvation of education - an easy way to customize learning to individual needs - it rarely lives up to this broad expectation" (Healey, 1999, p. 398).

When computers were introduced in classrooms, the emphasis was on the computers and software. Increasingly more consideration was given to how the technology would integrate into instruction and influence assessment. The contribution of ICT needs to be mediated by human, organizational, and educational issues. Increasingly teachers found strategic ways to use the new technologies and their use in teaching and learning changed as teachers themselves changed. This evolution was tied closely to changes in teachers' beliefs about learning, about teacher-student roles, and about instructional practice (Haymore Sandholtz, Ringstaff, \& Dwyer, 1997).

Table 1

List of participating schools and partner institutions involved in the pedagogical framework design, implementation and validation.

\begin{tabular}{|c|c|c|c|}
\hline Country & School(s) & $\begin{array}{l}\text { Age of students } \\
\text { involved }\end{array}$ & Partner Institution(s) \\
\hline Bulgaria & $\begin{array}{l}134 \text { Hebrew and English Language School 'Dimcho } \\
\text { Debelainov' } \\
\text { National High School of Mathematics and Science 'Acad. L. } \\
\text { Tchakalov' }\end{array}$ & 16,17 & $\begin{array}{l}\text { Center for Information Society Technologies, FMI, University of } \\
\text { Sofia }\end{array}$ \\
\hline Cyprus & The English School & 17 & University of Cyprus \\
\hline Croatia & Elementary School 'Spinut' & 13,14 & Faculty of Science, University of Split \\
\hline Germany & $\begin{array}{l}\text { Berüfliche Schule Elektrotechnik / Elektronik } \\
\text { Erasmus-Gymnasium Rostock }\end{array}$ & $15,16,18,19$ & $\begin{array}{l}\text { Landesinitiative Neue Kommunikationswege Mecklenburg- } \\
\text { Vorpommern e.V }\end{array}$ \\
\hline Greece & Ellinogermaniki Agogi School & 13,16 & Ellinogermaniki Agogi S.A \\
\hline Latvia & Riga 3. secondary school & 16,17 & Riga Technical University \\
\hline Lithuania & Kaunas University of Technology Gymnasium & 17,18 & Kaunas University of Technology \\
\hline Malta & $\begin{array}{l}\text { Stella Maris College, Gzira - Malta } \\
\text { Margaret Mortimer, Girls' Junior Lyceum, Sta Lucija - } \\
\text { Malta }\end{array}$ & 13,14 & Centre for Literacy, University of Malta \\
\hline Slovenia & Gimnazija in ekonomska srednja šola, Trbovlje & $15,16,17$ & Faculty of Social Sciences, University of Ljubljana \\
\hline $\begin{array}{l}\text { United } \\
\text { Kingdom }\end{array}$ & $\begin{array}{l}\text { King Edward VI School } \\
\text { Lynn Grove VA High School }\end{array}$ & 15 & $\begin{array}{l}\text { Cambridge Training and Development Ltd. } \\
\text { Centre of Applied Research in Education, University of East } \\
\text { Anglia }\end{array}$ \\
\hline
\end{tabular}




\subsection{The effects of ICT in education}

Grégoire, Bracewell, and Lafferière (1996) reviewed a large number of papers and research studies regarding the integration of ICT within the classroom setting and identified fourteen outcomes. These are:

1. Various intellectual skills including problem solving, reasoning and creativity.

2. Specific and finer learning of particular skills and subjects.

3. Students demonstrate higher interest in activities which are presented and taught using ICT.

4. Students have a longer attention span and have higher degrees of concentration when activities are carried out using ICT.

5. Interest in research is enhanced due to the easy accessibility to resources through ICT.

6. Cooperation amongst students is brought about through the use of ICT within the classroom, with different classrooms and even with different schools.

7. Due to processes such as simulation, virtual manipulation, merging of data and graphic representation, the assimilation of various aspects is brought about, hence leading to more profound learning and understanding.

8. Through the use of ICT, teachers are able to access and utilize a vast selection of instructional resources.

9. Teachers' communication and cooperation is improved with colleagues within and outside the school through ICT.

10. The orientation of planning for teachers is gauged more towards students performing real work in cooperation with other students rather than individualistic work.

11. The relationship of the teacher changes to that of facilitator and guide with a more interactive role between the teacher and student.

12. Through ICT, the learning process begins to be viewed as continuous research rather than a series of facts that are to be learnt.

13. A positive attitude towards assessment is instilled, while more demanding assessment methods are put into place.

14. The strengths and weaknesses of a student may be easily and rapidly identified through the use of ICT tools.

\subsubsection{Impact of ICT on attainment and motivation}

ICT has been shown to have an impact on both attainment and motivation. Harrison et al. (2002) carried out a nationwide research in the UK consisting of 60 schools and 2100 pupils, investigating the effects of ICT within the school setting. Results showed that there was a statistically significant positive relationship between gain in scores and the use of ICT in: English KS2, Science KS4, and Design and Technology KS4. Passey, Rogers, Machell, and McHugh (2004) carried out research in 17 schools including 1206 pupils and 121 educators. The results indicated that implementing ICT within the learning process led to positive motivational outcomes. Higher motivation was observed when ICT was implemented in writing, research and presentation work. When ICT was utilized in both teaching and learning, higher levels of motivation were also observed. Motivation was found to be independent of gender and ethnic background, but was affected by socio-economic status due to exposure to ICT outside the school setting. Furthermore, the study found that students experienced high levels of motivation when using ICT to achieve personal learning goals and to gain positive feedback. Passey et al.(2004) concluded that using ICT helped pupils to draw on positive motivation and could offer a means by which pupils could envisage success. This study also showed that the school staff was more motivated to work and ICT helped make classroom management easier.

Sime and Priestley (2005) found that students were involved and engaged in activities for longer periods of time and took great pride in their work when ICT was used in learning. Furthermore, Hayward, Alty, Pearson, and Martin (2003) found that $48 \%$ of KS3 students and above believed that ICT motivated them in their schoolwork and 76\% of KS1 and two children stated that schoolwork was more enjoyable when ICT was implemented. 62\% of KS3 children stated that through ICT they understood easily the topic being learnt and were proud of the work they produced.

\subsubsection{Impact of ICT on learning and creativity}

Dimitrova, Mimirinis, and Murphy (2004) found that through the implementation of ICT, students were offered flexibility in the learning process as they were given a choice of tools from which to use to bring about learning. They found that different students learn differently and make use of the different tools available in different times and places, making the learning process more flexible and enjoyable. On the other hand, it was noted that some students had difficulties adapting to learning through ICT, especially those students who were more accustomed to traditional approaches in teaching and those students that preferred face-to-face interaction. With the implementation of ICT within classrooms, children are working more independently rather than in groups (Hayes, 2007). Loveless (2002) explored how ICT can enhance creativity. They found that ICT was being exploited in the creative processes of developing ideas, making connections, collaboration, communication and evaluation and creating and making.

Volery and Lord (2000) found a statistically significant relationship between teaching effectiveness and technology when conducting research on an online teaching course. The key factors contributing to the positive outcomes of online learning, were namely ease of access and navigation, level of interaction and interface design, the instructor, including his/her attitudes towards students, the level of competence in computer use and classroom interaction, and the previous use of technology by the student. These results imply a shift within the role of the educator, from a person giving out facts to a "learning catalyst" (Volery and Lord, 2000, p. 223).

Although research has shown a considerable number of positive outcomes of the use of ICT within the classroom setting, Hayes (2007) points out that the integration of ICT is highly dependent on the teachers who have to master these new tools and to reach their teaching objectives through their use. Sanchez and Salinas (2008) noted that although teachers were interested in the use of ICT, its implementation within everyday teaching was limited and simple. "If ICT is to transform students' learning opportunities, ways must be found to first transform teachers' learning opportunities” (Hayes, 2007, p. 392).

\subsubsection{Autonomous learning}

In recent years, a fundamental objective of teaching and learning has been to enhance the control of the learner over the learning process, that is to bring about learner autonomy. This notion is a fast changing one as new research and theories shed new light and give rise to new practises. Little (1991) has described autonomy as essentially "a capacity for detachment, critical reflection, decision-making and 
independent action". Holec (1988) refers to autonomy as "the ability to take charge of one's own learning". It is not something we are born with but it has to be learnt.

The appropriate use of new technologies, particularly ICT, has the potential to increase learner autonomy. They provide students with a much better opportunity for control over and initiative in language learning. ICT can help develop students' learning skills and help them to acquire a critical learning perspective. Recent studies indicate that electronically-mediated learning environments are more learner-oriented than teacher-oriented ones. Through the use of multimedia tools, the responsibility for learning is transferred to the student and the teacher facilitates the learning by acting as a facilitator of learning, resource person, and guide. This attitude shift makes the student's role more proactive rather than reactive. Studies have shown also that learning is enhanced when students have extensive interaction with each other and with the teacher (e.g. Gomez in Kannan \& Bento, 1996). Learners are bombarded with so much information, that knowing how to find and interpret facts has become more important than memorising them.

The new technologies have extended the boundaries of the classroom with regard to both space and time. Hanson-Smith (2000) points out that technology can enrich the usual four-walled classroom world with explorations of the boundless greater world outside. Research in a variety of classroom and organizational settings has provided evidence that the introduction of computers has the greatest impact on learning when the computers are an integral component of a new way of learning and operating instead of being used in an isolated manner (Haymore Sandholtz et al., 1997; Zuboff, 1988 in Warschauer, Shetzer, \& Meloni, 2000). This involves the concept of "integrative Computer Assisted Language Learning" (Warschauer et al., 2000), in which the computer is used naturally and regularly together with other tools and media "serving the creation of an enriched workplace for accessing resources and using language constructively" (Barson \& Debski, 1996 in Warschauer et al., 2000). This does not mean that technology will replace teachers. In fact they still have a very important role to play. Students, by and large, eagerly embrace the universe technology opens to them, but in most situations, teachers are the gatekeepers of this rich storehouse of learning. Their hard work, planning, and organizing are the pathway for students to enter this enriched new environment (Hanson-Smith, 2000).

\subsubsection{A new role for teachers}

A pedagogical theory framework is required for the effective introduction of technology in education. In this way teachers can be supported and guided to best exploit its tools in the most adequate and effective way. Mayes (2001) reminds us that "it is not new pedagogies that we need, but new ways of providing existing pedagogy efficiently and flexibly". The challenge is to reproduce the rich pedagogical experience offered in the context of a tutorial by an effective teacher to a large number of students from diverse settings. All this requires a dramatic change in the teacher's role. Technological innovation can only be harnessed by those teachers who, as Hewer and Shield (in Atkinson, 2001) argue, "can adapt to the changed role of facilitator and manager of learning, rather than knowledge source". Mällinen (2001) sees the role of the teacher as now changing from "the sage on the stage" to a "guide on the side". This is not only due to new educational technologies but also to adapt to a society, which is itself changing. It is the school's responsibility to equip students with the necessary theoretical basis and skills that enable them to make innovative decisions in new situations, where rote solutions no longer work for the new, complex problems of a changing labour market (Mällinen, 2001).

\subsubsection{Supports for change}

Teachers who make the most changes in the classroom are those who have the greatest level of support. Supports need to be at the levels of pedagogical design, coordinator support, administrative support which is to create a shared school vision, provide time for learning, show interest, arrange technical support and ease access problems and the provision of the required resources and appropriate continuing professional development.

With the introduction of innovative features of Web 2.0 current e-Learning solutions, mostly characterized by single user and centred data-download, have changed and developed further. Principles of the Web 2.0, like the ability to connect people, to distribute information world wide and to support communicating and collaborating user groups, have similarities to modern educational theories (Ullrich et al., 2008). Constructivist perspectives and activity theory in particular emphasise the importance of active learning, while methods like collaborative learning and problem-based learning in real-world contexts (situated learning) as well as learning through games and entertainment are becoming increasingly popular. With this trend the challenge is in the development of e-Learning solutions which take the integration of mobile learning into consideration.

The system we present in this paper has sought to create this support structure to ensure maximal benefits of the e-/m-Learning system for teaching and learning.

\subsection{Background work to pedagogical framework design}

Despite unquestionable positive effects of technologies on diverse educational aspects, concerns have been voiced that the push towards a wider embedding of ICT in education may ignore issues of the appropriate uses of these resources, $c f$. (Conole \& Oliver, 1998). What is needed is sound and compelling pedagogy-driven approach for embedding ICT in learning and teaching. Although a single, generic model/approach is unlikely to fit the variety of pedagogical approaches, assessment techniques and subject differences, a commitment to a set of ideas and principles which seem credible and/or appropriate, offers the possibility of more pedagogically sound e-Learning practices. The use of a kind of a "guiding support", specifically a pedagogical framework, which underpins technologies could assist in identifying the requirements of e-Learning systems that support the teachers in how to teach as well as students how to learn. A number of frameworks have been proposed ranging from the ones intended to form the focus of discussion of ICT-related issues and not as a procedure by which this is achieved to the ones which offer a more structured procedure for designing e-Learning environments. They may be more or less structured, with aspects nested within one another hierarchically or related via non-hierarchical dependencies. Goodyear (1999) claims that a pedagogical framework needs to be understood in relation to concrete educational activity (i.e. educational setting) in a real world setting (i.e. organizational context). Its four elements - philosophy, high level pedagogy, pedagogical strategy and pedagogical tactics need not be tightly intertwined. According to Goodyear the loose connections of elements gives space within which stakeholders can be both disciplined and creative, listen to instincts and make them accountable to others. Lim (2001) proposed the framework for integrating technologies in teaching and learning comprised of six components: institutional support, training and development, designing for 
integration, approach to integration of technologies, paradigm shifts in education and technological development together with cultural change among educators.

Sharma and Mishra (2007) present a pedagogical framework for e-Learning named Experience-Reflect-Interact-Construct (ERIC), where the system provides opportunities for the learning experience to be accessed from anywhere, anytime through learning objects in different web-enabled formats, followed by working on learner reflection activity designed a priori. After performing the activity, the learner should be engaged in both "synchronous" and "asynchronous" interaction, leading to construction of his/her learning through group works, presentations, projects and other creative activities.

Bradley and Oliver (2002) consider pedagogical models which move from a simple model, relaying on core computer-based materials (assessed by multiple-choice questions with optional work-based learning) to a more sophisticated model that integrates different forms of learning. According to them a pedagogic model should be viewed as a guiding framework, since each group of stakeholders will relate it to their own experience and expertise. The I CARE pedagogical framework of Hoffman and Ritchie (1998) was distilled from basic instructional design practice, adapting five steps of instruction: introduction, connect, apply, reflect and extend. It explicitly recognizes "learners' prerogative to organise their course time around work, family and other commitments, while maintaining a modular structure of 'do-able chunks' arranged in a progressive series".

Conole and Oliver (1998) proposed to unify three similar existing approaches resulting in a combined framework for embedding ICT. In their proposal, the integration to be structured is to include the steps already identified in existent approaches: establish current course overview; for each activity, consider whether to write, buy or adopt supporting materials; select appropriate assessment models; link the individual learning scenarios to form a unified course; identify student access needs and skill requirements; establish resource requirements and infrastructure requirements where appropriate. Furthermore, in the proposed single, coherent and inclusive framework intended for use by practitioners wanting to embed ICT into their courses, Conole and Oliver added two new elements - shift of the focus of analysis to "learning scenarios" rather than courses as well as the analysis of course description in terms of its aims and outcomes.

Nevertheless, the pedagogical framework that underpins technologies should build on learning communities and support student-centred curriculum, effectively providing individual learning approaches of the increasingly diverse target population. The present study has sought to devise a "sound and compelling pedagogy-driven approach for embedding ICT in learning and teaching". It has sought to develop a pedagogical framework (PF) which stems from the experience of a number of educators and learners located in a number of schools systems across Europe. A support system of teacher education and relevant curricular resources was put in place for the actual implementation of the PF in real school contexts. Validation of the learning outcomes was carried out by both practitioners and experts. The design, implementation and validation of an empirically-tested PF for e-/m-Learning are presented in the following sections. The framework represents an essential part of the UNITE e-Learning system conceptualization and development.

\section{Pedagogical framework design}

When designing the pedagogical framework, three main aspects were taken into account. First, the existing state-of-the-art (SOTA) models of exploitation of the potential of new technologies in pedagogy and the list of acquired user requirements (see sub ${ }^{* * *}$ Section 3.2.1) related to the PF were analysed thoroughly. Both the SOTA models in pedagogy and the user requirements are available in (UNITE deliverable D1, 2006). Second, in order to acknowledge the importance of the local contexts of the network of schools, national and school specifics regarding educational characteristics and existing pedagogical practices were collected and formulated. Consequently, a common framework within the context of our research has been developed. Third, pedagogical experts analysed the wider educational context in order to find out which components should in addition constitute a "best-practice" PF.

As a result of the analysis of the above aspects, the PF with appropriate and relevant theories and practices was developed. The derived framework consists of five components illustrated in Fig. 1: (i) pedagogical framework context, (ii), pedagogical approaches, (iii) assessment techniques, (iv) teacher education and (v) current pedagogical practices implemented in national curricula (Ćukušić, Granić, Pagden, Walker, \& Zammit, 2006). These five components of the UNITE's pedagogical framework, described in following sections, can be summarized as follows:

- Pedagogical framework context: UNITE's PF is situated in a broad context. This includes: an emphasis on the empowerment of learners through the increased interaction/communication that is supported by the system; an interest in the affordances of mobile devices inside and outside the classroom and an awareness of the need to understand traditional practices in order to challenge them.

- Pedagogical approaches (both for m-Learning ande-Learning): based on what our users have indicated and our analysis of the broader context we maintain that UNITE should be used to promote active learning in collaborative and individual contexts with an emphasis on student autonomy. The concept of "active learning" encompasses ideas about knowledge acquisition (e.g. constructivism), the management of learning activities (e.g. blended learning) and the importance of the social dimension (e.g. collaborative learning). The potential of $\mathrm{m}$-Learning and the particular issues that it raises were addressed in UNITE through the development of coherent e-Learning scenarios that incorporated the use of mobile devices in a way that is relevant, purposeful and manageable in a school context.

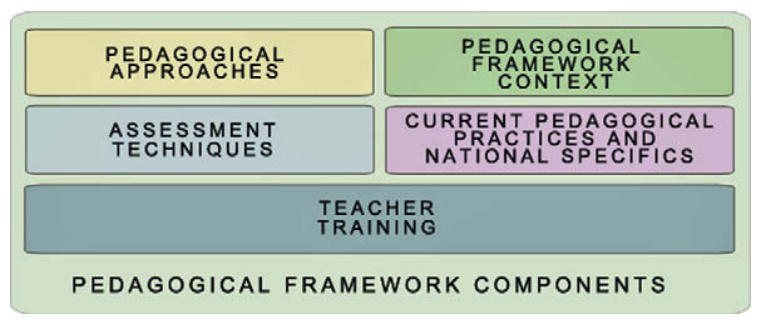

Fig. 1. Components of the Pedagogical Framework. 
- Assessment techniques: Four types of assessment were considered: computer-based assessment, self-assessment, peer-assessment and tutor-assessment. Whereas UNITE supported low-level computer-based assessment (e.g. multiple choice quizzes), e-Learning scenarios sought to maximise the potential of the system to support a range of formative assessment strategies including "collaborative assessment". This was a significant challenge in the context of compulsory schooling where traditional forms of assessment are the norm (i.e. summative and teacher centred).

- Current pedagogical practices implemented in national curricula and national specifics: National and school specifics regarding educational characteristics and existing pedagogical practices were taken into account in order to formulate a common pedagogical framework. Different aspects of national specifics were considered: national curricula and school educational policy plans, existing pedagogical practices in school, technical infrastructure and future UNITE users. National dimensions were identified and in the pedagogical framework implementation phase harmonisation procedures that helped to integrate UNITE in daily class activities were developed.

- Teacher training: Teacher training was also included in the pedagogical framework design process in order to help teachers get started and support their ongoing work. Techniques and methods for the building of a learning community and to encourage the participants to explore the system as well as the related materials were formulated in the implementation phase.

An integration of these five PF components enables the generation of a set of parameters which drive and guide the production of learning scenarios. The learning scenario is a crucial mechanism that holds together both sides of the development process (i.e. the pedagogical and the technical) and in this way it is pedagogically driven. The PF design process, the framework components and the associated outcomes are illustrated in Fig. 2 and presented in the following subsections. Importance is given to user requirements for PF design and a brief insight into main pedagogical approaches and assessment techniques employed in the e-Learning system is offered.

\subsection{Context of the pedagogical framework}

The context of the PF defines areas that influence the framework itself and formed the basis for further development of the theories of the project. In order to understand and challenge traditional practices, specific aspects of learning processes that the pedagogical model focuses on along with theoretical and pedagogical aspects of e-Learning and mobile learning (m-Learning) were analysed. As a consequence, the context of the PF presents for example how the project focuses on the learning process, e-/m-Learning theoretical and pedagogical aspects, motivational factors and strengths and weaknesses of e-/m-Learning.

In the following section, the emphasis is on e-/m-Learning strengths and weaknesses as it influences the most other framework components. To understand better the strengths and weaknesses of e-Learning systems and to isolate the key "issues" that are of importance to the project and PF, a preliminary SWOT analysis of e-Learning implementation cases was performed. It was applied as an additional checklist for the scenario developers and was used in the PF implementation phase. According to Lehofer (2005), e-Learning should already be transforming pedagogical processes, breaking down barriers, opening-up access, supporting mobility, increasing personalization, giving greater flexibility in time and space, supporting intercultural dialogue, strengthening social cohesion, facilitating partnerships, etc. Some are in disagreement with this vision of today's e-Learning systems (see Haywood, 2005; Kohn, 2005; Mansberger, Bauer, \& Heine, 2006). Strengths, weaknesses, opportunities and threats (SWOT) analysis was used as a planning tool in order to evaluate the internal project's strengths, weaknesses as well as external opportunities and threats. Some of the conclusions drawn from the resulting SWOT matrix lay emphasis on the fact that (i) blended learning, which uses the best of traditional and e-Learning methods, is the ideal teaching concept for the future and that (ii) the implementation of the e-Learning system does not save time but does create new opportunities for cooperation at the national and international levels (Ćukušić et al., 2006). One of the weaknesses, which emerged from the SWOT analysis, is not having a "clear vision". Schools often fail to recognize potential uses of new technologies and have difficulties in developing, publishing and maintaining their own e-Learning policies and strategies. Bearing in mind threats and weaknesses from the produced matrix, the majority of which are of an organizational nature, implementation procedures addressed the development of integration plans and methods for the seamless implementation of ICT into the teaching and learning processes, support mechanisms, various recommendations and a like.

\subsection{Pedagogical approaches and assessment techniques}

The two fundamental parts of the PF (Fig. 1) are the pedagogical approaches and assessment techniques. Four key pedagogical approaches to e-/m-Learning are combined to build a variety of different learning environments to suit the learning content, the needs of the learners and the curriculum requirements. Together with the four assessment techniques, they are the most important guide to the production and use of scenarios - the main instrument for the educational implementation of the system. This section is based on the views of the users (teachers) and our analysis of the broader context. It outlines the pedagogical approaches the project has introduced and promoted through its PF as well as the assessment techniques employed to assess the students' knowledge.

\subsubsection{User requirements as prerequisite for pedagogical framework design}

An extensive survey of user requirements collected and formulated in a Europe-wide network of 14 schools formed the basis of the system design. The user requirements specification phase provided a sound foundation for the design and the implementation/development of project outcomes, embracing the pedagogical framework (PF), the e-Learning scenarios (LS) and the technical platform (TP). A highly systematic and thorough approach to the requirement specification was applied, involving end-users, experts and developers. A bottom-up, data-driven method was chosen to reflect the real needs of users, whereas a clustering methodology was developed and applied in order to integrate and process (filtering, arrangement, categorization and prioritization) results from user and expert feedback (Iliev, Gachev, \& Nikolova, 2007).

A list of user requirements related to the PF formed the basis for the first phase of the design. Requirements were classified and categorized using a simple matrix (see Fig. 3), as one of many possible ways of categorization. Matrix rows are associated with autonomous/ directed learning and active/passive learning on the one hand, while on the other hand its columns are related to individualised/collaborative learning. Consequently, such categorization illustrates how for example collaborative learning can take place with diverse degrees of student autonomy, ranging from autonomous to directed learning. 
UNITE DESIGN PHASE

\begin{tabular}{l}
$\begin{array}{l}\text { State-of-the-art } \\
\text { (SOTA) in } \\
\text { eLearning }\end{array}$ \\
\hline
\end{tabular}

\begin{tabular}{|c|c|c|}
\hline \multicolumn{3}{|c|}{ USER REQUIREMENTS related to } \\
\hline $\begin{array}{l}\text { Pedagogical Framework } \\
\text { (PF) }\end{array}$ & $\begin{array}{l}\text { e-Learning Scenarios } \\
\text { (LS) }\end{array}$ & $\begin{array}{l}\text { Technological Platform } \\
\text { (TP) }\end{array}$ \\
\hline
\end{tabular}

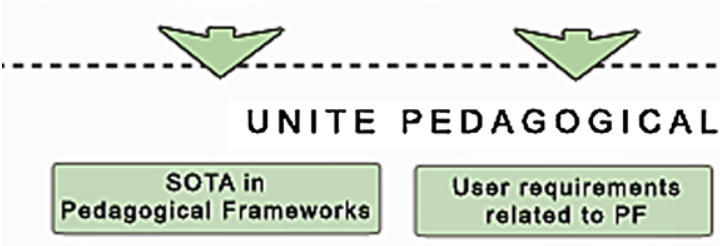

User requirements:

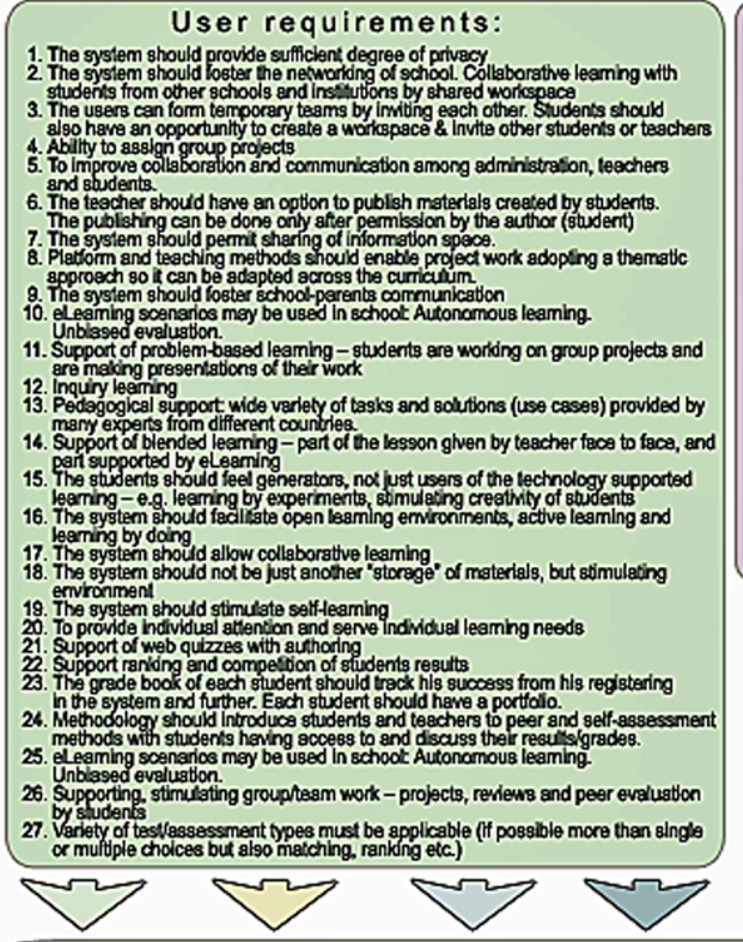

FRAMEWORK DESIGN

\begin{tabular}{|c|c|}
\hline & $\begin{array}{c}\text { National specifics } \\
\text { questionnaire }\end{array}$ \\
\hline 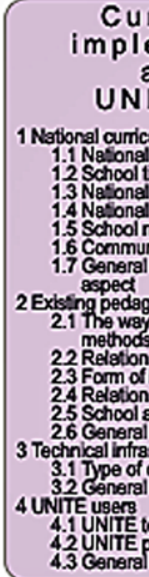 & 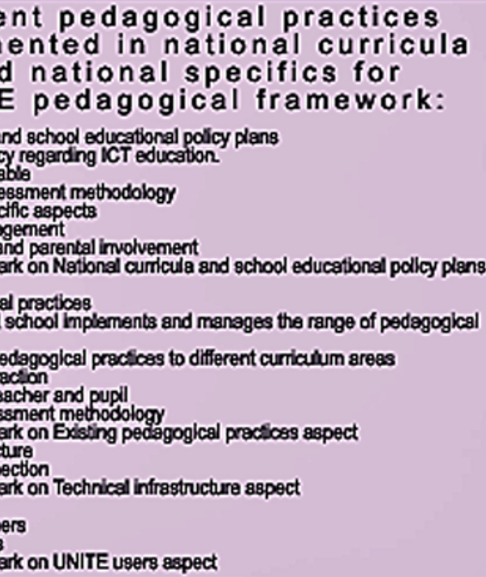 \\
\hline
\end{tabular}

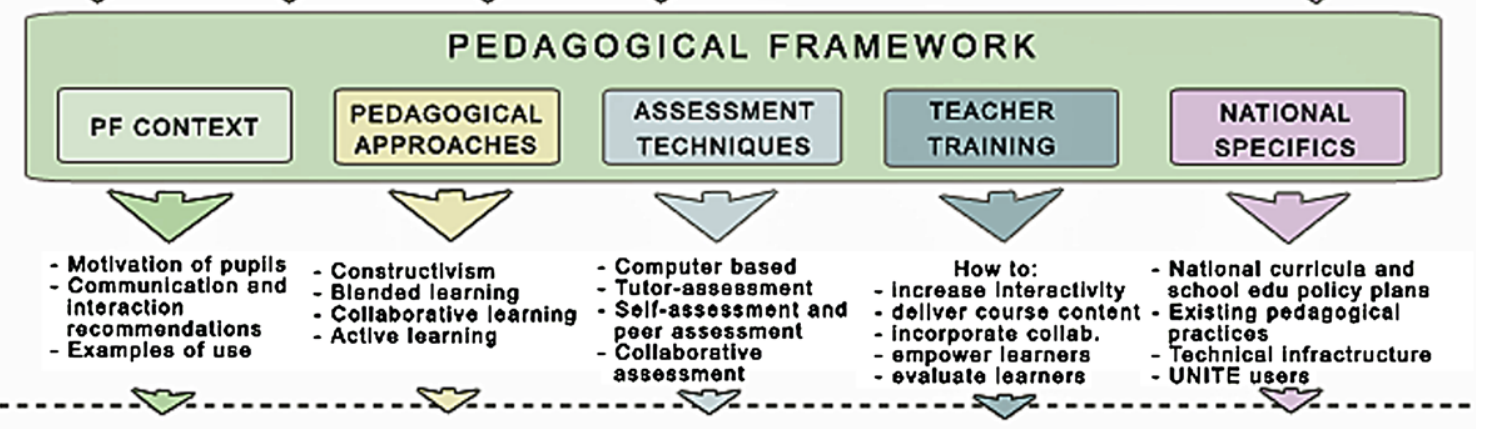

\section{UNITE PEDAGOGICAL FRAMEWORK IMPLEMENTATION}

Fig. 2. Pedagogical framework design of UNITE - approach and outcomes (Granić \& Ćukušić, 2007b).

Taking into account eight possible combinations of learning types and requirements categorizations, it was established that teachers want to use the system while applying autonomous and active learning principles in both individual and collaborative contexts. Accordingly, teachers can implement e-/m-Learning scenarios that encourage autonomous, either individualised and/or group learning, namely collaborative decision making process about how to proceed with learning. In addition, scenarios engage individuals and/or groups in enquiry based learning, problem solving, case studies and similar tasks, all of which are active learning techniques. This of course would assume a concept of the student as a "producer" or "constructor" of knowledge. Furthermore, user requirements related to the PF also conveyed that teachers would like to practise blended learning and/or flexible learning in their daily practice. Although this has more to do with what the teacher does or how (s)he uses available resources, blended learning is presented as one of the PF approaches.

Consequently, principles of constructivist theory, blended, collaborative and active learning (all derived from user requirements) are the four key pedagogical principles, praxis or theories which represent one of the PF components of UNITE. Those are the ones which PF integrates into the learning scenarios and promotes in the implementation phase. 


\section{LEARNING}

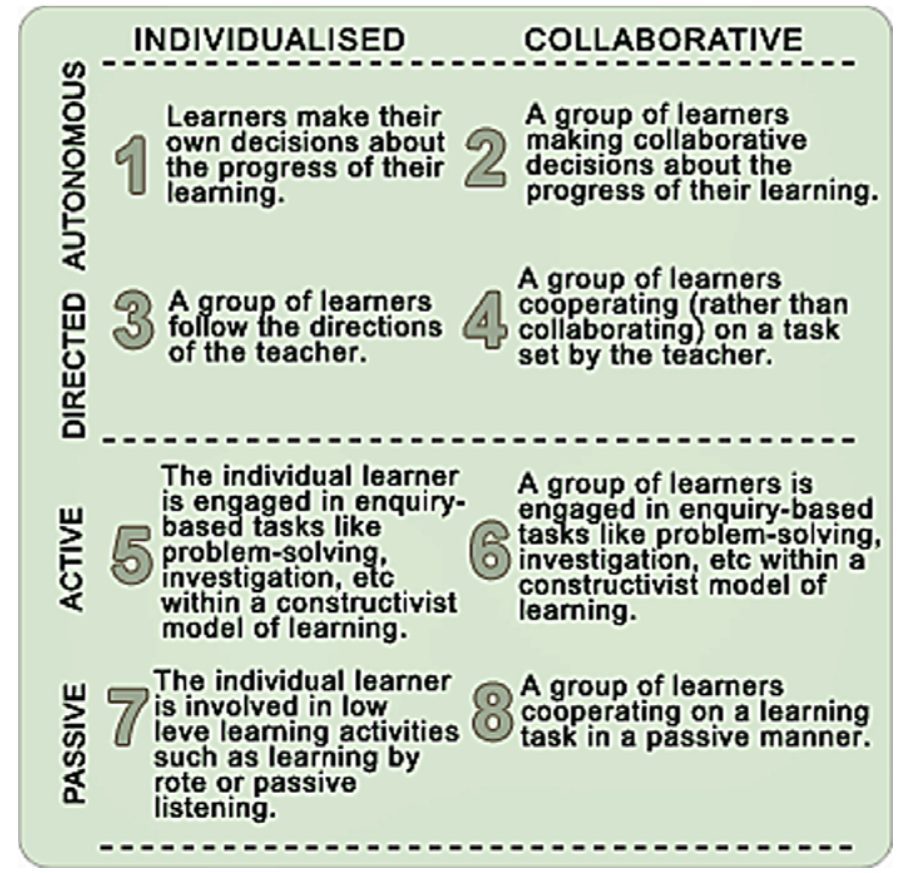

Fig. 3. Matrix used to categorize user requirements related to Pedagogical Framework

Assessment is another very important part of the learning process in general. Therefore while analysing user requirements related to the $\mathrm{PF}$, the focus was also on assessment and knowledge evaluation techniques. From the derived user requirements, it was concluded that users would like to make use of four diverse types of assessment in particular: computer-based assessment, tutor-assessment, self-assessment and peer-assessment. These assessment techniques, which are implemented within e-Learning scenarios, are together with the pedagogical approaches the main components of the PF since they directly influence and inform the learning and teaching process. Any pedagogical innovation should be made clear in pedagogy or assessment applied in or beyond the everyday classroom teaching environment. Like every "best-practice" project, UNITE draws on iterative design process advantages. This means that continuous feedback from teachers and students informed the design decisions, both technology and pedagogy related, all the way through the later phases of the project. The key pedagogical approaches along with the employed assessment techniques are briefly described in subsequent sections.

\subsubsection{Pedagogical approaches}

Pedagogical approaches, as principles and praxis which the PF integrates into e-Learning scenarios and promotes in the implementation phase as well, are presented in the following.

3.2.2.1. Constructivism. Constructivism embraces the concept where students create knowledge and meaning through their interaction with one another, their environment and with teachers (Alessi \& Trollip, 2001). Teachers can be thought of as being coaches, facilitators or even partners with learners in the learning process. Constructivism in the classroom promotes active learning processes that lead not only to the construction of a single meaning but also to a contextual system of meaning (Mason, 2002). Consequently, the constructivist approach to teaching and learning forms the theoretical basis upon which the pedagogical model is designed. It was implemented in various educational contexts in diverse ways (hands-on learning, reflection, interaction, investigation and analysis, cf. e.g. (Gray, 1997; Ullrich, 2004)) requiring from teachers to design instruction accordingly, thus supporting such a philosophy of teaching and learning. This approach emphasizes the fact that in a constructivist classroom, teacher and student share responsibility and decision making as well as demonstrate mutual respect.

3.2.2.2. Blended learning. The teachers used the system as technological enhancement to their everyday teaching process. They brought together the best of traditional, i.e. face-to-face, and online communication according to the principles of blended learning. In blended learning one part of the educational communication takes place in a classroom, while the other takes place online. It has been argued that up to $80 \%$ of verbal exchanges in the classroom are attributed to the teacher (Grogan, 2005). Conversely, in e-Learning courses teachers do not "speak" more than their students (Marcelo, 2006), suggesting that learners, who are too shy to contribute in the classroom, feel more empowered to do it online (Jonassen, 1996). Therefore, blended learning seems to be an ideal teaching concept for the future and its employment in the project affected and empowered students to contribute online extensively.

3.2.2.3. Collaborative learning. Collaborative learning (Prince, 2004) is a term used for a variety of educational approaches involving joint intellectual effort by students or students and teachers together. It covers a number of approaches with variability in the amount of in-class or out-of-class time built around groups of students working and mutually searching for understanding, solutions and/or meanings. Some forms of collaborative problem solving implemented in the project include: (i) guided design as a very structured approach to group problem solving where students, working in small groups, practice decision-making in sequenced tasks, with detailed feedback at every step, (ii) cases, stories or real life situations setting up a problem for students to analyse and resolve in class or in study group session and (iii) 
peer writing involving students working in small groups at every stage of the writing process, formulating ideas, clarifying their positions, testing an argument or focusing a thesis statement, $c f$. e.g. (Prince, 2004).

3.2.2.4. Active learning. Active learning is defined as "any instructional method that engages students in the learning process" (Prince, 2004). It requires from students to think about what they are doing as opposed to passively receiving information from teacher in traditional teaching methods. There is evidence of the importance of and the positive effects of active learning on the quality of learning, innovations in education and the like. Some studies find higher class scores on items presented via active learning (Yoder \& Hochevar, 2005), while others see the benefits of active learning to be a valuable contribution to the development of independent learning skills and the ability to apply knowledge, preparing students for future careers (Sivan, Wong Leung, \& Woon, 2000).

Learning scenarios engaged individuals and/or groups in various forms of active learning like problem-solving, case studies and enquiry based learning, which contributed to the development of qualities like critical thinking and problem-solving. Through these activities, students are able to discover new information and become self-managed learners.

\subsubsection{Assessment techniques}

Besides the introduced pedagogical principles and approaches, the PF supports also the use of summative and particularly formative assessments in teaching and learning. Summative assessment, also referred to as "assessment for accountability", through oral examinations and written tests, is still the predominant means of evaluating students' achievements. It is usually used at the end of a teaching unit to determine what has been learnt by the student.

On the other hand, problem-solving, stimulations and project work with formative or on-going evaluation present a step forward in order to acknowledge that assessment is actually part of the learning process. Formative assessment, often referred to as "assessment for learning", is defined as ". . . all activities undertaken by teachers and/or by their students, which provide information to be used as feedback to modify the teaching and learning activities in which they are engaged" (Black \& Wiliam, 1998). The assessment techniques promoted through the learning scenarios are briefly presented in the following.

3.2.3.1. Computer-based assessment. Implementation of online, computer-based assessment requires time and creativity to produce a good set of questions bearing in mind diverse issues: learning objectives, which competencies to be mediated to students, the extent to which the competencies should be mastered by students, reliability in grading, prevention of cheating, examination construction and the like, $c f$. (Mödritscher, Spiel, \& Garcia-Barrios, 2006). E-assessment enables easier and faster processing and marking of students' responses as well as offering immediate feedback about students' understanding of subject matter. Another valuable advantage of an automatic online assessment process is the elimination of subjectivity that can be present in a traditional assessment process.

Quizzes are one type of computer-based assessment techniques that were introduced in UNITE. Multiple-choice type tests or quiz type questions can be assigned: (i) at the beginning of a course for diagnostic purposes to indicate any areas where prerequisite knowledge may be inadequate, (ii) during a course in order to measure progress in understanding and/or (iii) at the end of a course to assist in revision.

Notwithstanding all this the authentication of student identification and detection of plagiarised digital material are the two obvious challenges (Mödritscher et al., 2006).

3.2.3.2. Tutor-assessment. e-Learning systems offer students exceptional opportunities for individual communication with their teachers/ tutors. Other than using UNITE platform functionalities, teachers can now be contacted via e-mail 24/7 and as a result students actually always have a personal tutor available. Since the assessment and the grading are not realised only by computer-based tests, teachers use open-ended questions as well (e.g. writing essays or submitting some project work). In such cases the evaluation process is extremely time-consuming and self-/peer-assessment could ease the teacher's assessment overload.

3.2.3.3. Self-assessment. Student involvement in their own assessment is an important part of their preparation for life and future work. Through self-assessment, which goes contrary to the traditional one where written tests and oral exams still prevail, students can track their personal development and deepen their learning experience. They take more responsibility for their own learning and become more aware of their own knowledge gaps (if any) too, since they assess themselves in relation to the course objectives. With UNITE, students complete exercises at their own pace and receive personalized feedback messages. Moreover, they are actively involved in making decisions about their own assessment criteria as well as in judging their own and others' work as well $c f$. (McConnell, 2000).

3.2.3.4. Peer-assessment. In peer-assessment students are engaged in helping each other to develop, review and assess other's course work. The UNITE system is well suited for peer-assessment because in forums students can easily share and comment on other students work and contributions. They can read forum messages, receive direct feedback on their work and receive another perspective to a problem or a topic since they are confronted with many different views and perspectives. Forum discussions are more "relaxed" and can be used for lowstakes testing only. Exchange of ideas, evaluation and comments on the work of their student peers makes peer-assessment part of the learning process and a valuable resource for mutual learning. In order to overcome and avoid comments like "I don't like his/her work", explicit instructions on what and how to assess, what aspects of the work should be taken into account etc. should be provided.

All things considered, benefits of self-assessment and peer-assessment are vast: (i) as formative educational tools, self-/peer-assessments are more student-oriented, they reduce time expended by teacher and immediately provide feedback to a student, (ii) teachers can evaluate output of their courses more accurately, (iii) students become less dependent on their teachers, more responsible and autonomous and furthermore (iv) self-/peer-assessment helps to remove student/teacher barriers, enabling students to develop problem-solving and thinking skills by taking on more active roles and developing self awareness, $c f$. (McConnell, 2006).

\subsection{Teacher education}

Teacher education can enable and facilitate successful online teaching and is therefore introduced as an important part of the PF. The UNITE pedagogical team introduced teacher education in the first instance to help teachers get started on the system and to support their 
ongoing work. Face-to-face sessions were planned and delivered at the beginning (as local workshops) of the project as well as an international training event for teachers. The aim of these local sessions was to familiarise teachers with the PF and its implementation. At the international event teachers were involved in making their scenarios consistent with the constructivist approach to pedagogy of UNITE with an emphasis on active learning, collaboration and reflection. Therefore, rather than focus on the technology itself, greater attention was paid to what is enquired to be able to teach/learn online successfully. Most of the questions from teachers were expected to emerge in the beginning, when teachers were developing scenarios for themselves in schools.

Besides two interactive training opportunities, the Teachers' Handbook for the introduction of pedagogical innovations of the framework was produced. Areas covered by the handbook include: (i) implementation of pedagogical methods for e-Learning and m-Learning, embracing all aspects of planning, assessment and evaluation as well as (ii) recommendations and practical examples for classroom communication and interaction, new roles of teachers and students in the classroom and so on. More about the teacher training is presented in sections about the PF implementation and validation further below.

\subsection{Current pedagogical practices and national specifics}

The implementation of pedagogical changes in schools involved in the project has an impact on cultural aspects of the pedagogical process, assessment and pedagogical assumptions in general. Diverse educational systems address such issues differently. The schools were asked to complete a questionnaire in which national educational characteristics and existing pedagogical practice were key considerations.

Four categories of national specifics: (i) national curricula and school educational policy plans, (ii) existing pedagogical practices in schools, (iii) technical infrastructure and (iv) users' characteristics, formed a strong basis for consideration and comparison. Following the identification of national dimensions, harmonisation procedures that help to integrate the platform in daily activities were developed in the PF implementation phase. This necessary harmonisation procedure, required in order to integrate the system in daily activities, was related to different aspects like school organization issues, teacher education, parental and student expectations related to the system, national curricula requirements, assessment requirements and so on. Some of the key issues stemming from the received feedback relating to national and school specifics are presented here.

- National policy regarding ICT education: The fact that ICT is considered to be a priority area in the national educational policies of all the countries of the schools is perceived to be beneficial for the system implementation. However even in such situations the platform usage is not guaranteed and can be very poor. There is a minimum usability, accessibility and technical requirement for the platform to be successful. Beyond that it is even more important to have enthusiastic teachers and learners who believe that using ICT can make a difference to learning.

- National and school assessment methods: Although traditional evaluations like oral examinations and written tests are still predominant ways of student assessment, there are also efforts to implement more progressive models like problem-solving, formative and self-/peerassessment in the schools.

- Teacher-student relations: As pedagogy changes, students' perspective of the teacher changes as well. In most schools teachers are considered to be instructors, guides, facilitators or mentors who maintain different kinds of relationships with students. However, teachers still have their "audience" and authority. The UNITE platform and the PF contribute to the transformation of teacher-student relationships (especially in schools where classes are still held in a lecture-style format) creating an atmosphere which makes the school a learning community where close and respectful relationships are built. Conversely, some teachers may find these changing relations threatening to their authority.

- Technical infrastructure: In some parts of Europe the state of development of the technical infrastructure remains a difficulty either through poor server connections, slow Internet access, lack of equipment, etc. Although this aspect is catered for in the project as it provides a technical infrastructural solution, the type of connection, maintenance and similar issues still had to be considered. The connectivity in the schools was relatively good - this is in particular apparent in the School fact finding questionnaire (UNITE, 2006) - but the problem might be in accessing the system from home since students from four of the schools still accessed Internet using a dial-up connection.

In general it can be said that in the schools there are many ongoing initiatives and attempts to change the existing pedagogical practices and implement new models of interdisciplinary and multidisciplinary learning and teaching. However, the fact remains that strict timetables, prescribed methods of teaching and examination-oriented pedagogical practices render this shift a rather slow one. Listed "specifics" served as considerations for the PF implementation and were addressed both within the Teachers' Handbook (Ćukušić et al., 2007) and during teachers' training workshops. Some of the recommendations given to teachers included:

- Although recommended and prescribed by the national curriculum, new pedagogical approaches are hard to implement within their daily practice for some teachers (due to heavy teaching loads and tight schedules). In order to promote the implementation of new pedagogical approaches, cross-curricular activities that may save time could be considered. In the implementation phase more than ten learning scenarios were cross-curricular.

- In order to render the implementation of UNITE more successful, increased curricular freedom has to be given to teachers than is allowed in a highly centralised and hierarchical structure organised on many levels. In such an environment, it is hard to have enthusiastic teachers and learners who believe that using ICT can make a difference to learning and teaching. Implementation of pedagogical methods depends often on an open disposition of the teacher to try new, proposed pedagogical methods and assessment techniques.

- UNITE is potentially very useful as a means to improve the currently used forms of teacher student interaction, since it can support group work, discussions, practical assignments and the like. The system communication tools are in place to support these forms of interaction.

- Teachers have received technical and pedagogical support from the partner institutions. This was in response to some of the requests made by some of the teachers for additional help with the technology part of the system and the implementation of the scenarios. 
The above considerations were used to fine-tune the PF before the implementation phase. This has helped to ensure that the PF does not exist in a vacuum but is grounded within the professional teaching and learning experience of the Europe-wide network of schools and is geared to meet the specific needs of different national educational systems. This ensures that it gains increased face validity with teachers and other educational professionals.

\section{Pedagogical framework implementation}

The implementation of the pedagogical framework was accomplished through an incremental introduction coupled with continuous validation from April 2007 to June 2008 in at least two iterations (depending on the school). As stated earlier, the implementation phase comprised the joint work of the project partners (11 institutions collaborating directly with the schools) and school teachers involved in the creation and delivery of new and/or customised scenarios. A total of 44 learning scenarios describing either e- and/or m-Learning activities were developed during this time period. Several scenarios were reused and repeated in different learning contexts. It is obvious that the learning scenario is a central tool for e- and m-Learning implementation since it supports pedagogy and technical resources through a focus on concrete learning experiences/activities. Therefore the implementation of the framework focuses on the scenario management (the processes of planning, implementation and validation). In the first instance support materials were made available and teacher training on the international and national levels was provided to teachers.

\subsection{Resource materials}

In the first phase of the project the efforts of the pedagogical partners were focused, among other things, on the production of the support materials for teachers. Consequently, the teachers were able to make use of the fundamental materials delivered not only in English, but also in their mother tongue. These were the (i) UNITE scenario template and three initial scenario examples (Zoakou et al., 2006); (ii) Teachers' handbook (Ćukušić et al., 2007) and the matching Quick Guide poster version and online version of the Handbook; and (iii) Content development handbook (Tzanavari, 2007) and the matching Quick Guide poster version. Snapshots of these materials can be seen in Fig. 4.

- UNITE scenario template: Following a thorough literature review and state-of-the-art analysis, two possible scenario solutions (Beetham, 2004; Kynigos, 1995) were identified, merged and adapted further to match the particular needs of the project. The scenario template has two parts: one related to the curriculum area and the second linked with the learning activities. The activities, taking place during the scenario implementation, are matched with associated learning objectives, the tools/resources the teacher intends to use, the assessment strategies and the planned time-frame of the activities (Zoakou, Tzanavari, Papadopoulos, \& Sotiriou, 2007). The purpose of the template is to help teachers to organize the use of the e- and m-Learning system in the most efficient way and to reuse the scenario(s). That is why the quality of the scenario plan affects directly the scenario performance in terms of students' feedback, its reuse by others, flexibility in implementation (Zoakou et al., 2007).

- Teachers' handbook: The UNITE scenario template has been designed to encourage scenario development that is grounded in the pedagogical principles specified in the PF. In order to facilitate the implementation of the system the Teachers' Handbook was introduced prior to scenario development. The Handbook is intended as a practical guide and includes topics like: how to design a scenario, how to plan content production, guidance about some of the pedagogical approaches that teachers can use, information about how assessment can support learning, some practical online technical support and also a number of case studies to demonstrate how the system can enhance learning in the classroom and beyond. After the release of an easy-to-navigate and printable PDF version of the Handbook to the network of schools, another revised version of the Handbook was published online. It has been developed into a portal with many additional features for teachers (a pedagogical library, practical examples, as well as additional resources for further reading). The portal is accessible at http://pedagogy.unite-ist.org. A summary of the Handbook is available also as a Quick Guide.

- Content development handbook: The content development handbook is intended as a companion to the above-mentioned Teachers' handbook. This particular document defines a structure for the development of e- and m-Learning content, identification of the issues and the customisation of the scenarios. The distinction between the two documents is important - perhaps they are best described as a practical guide for UNITE platform users, the teachers' edition (shows the pedagogy behind the developed scenarios) and a technical support manual (how to develop own content). Producing content is not a trivial task since it requires certain skills and knowledge and includes steps such as: consideration of the particular learning objectives and the target audience, definition of the structure and relevant material collection, selection of an authoring tool, development, testing and evaluation as well as maintenance (Tzanavari, 2007).

\subsection{The UNITE platform/system}

UNITE platform is a web 2.0 e-Learning platform that seamlessly integrates three distinct technologies and their diverse functionalities into usable and effective e-/m-Learning environment (Hornung, Granić, Ćukušić, \& Nazemi, 2008): (i) an e-Learning portal, supporting the learning process and specifically group-oriented learning in classes of students, (ii) a knowledge repository, containing both the traditional e-Learning material (like assets, pages and courses), and also images shot during "learning at excursions", knowledge sharing sessions and best practices and (iii) a mobile learning component, that allows direct contact with other learners and to participate in mobile learning scenarios taking advantage of the m-Learning quizzes, mediaBoards and so on.

From a system design point of view, modularity and reusability of the system are very important and provide added value. Technically, the system is based on service-oriented architecture (SOA) concepts. In this way the configuration and integration of the three systems is possible and future enhancements are made easier. The e-Learning portal is based on Microcosmos, the enhanced knowledge repository comes from Infopool while the mobile learning component is implemented using the mediaBoard (Kouloumbis, Lu, \& Wunner, 2007). 


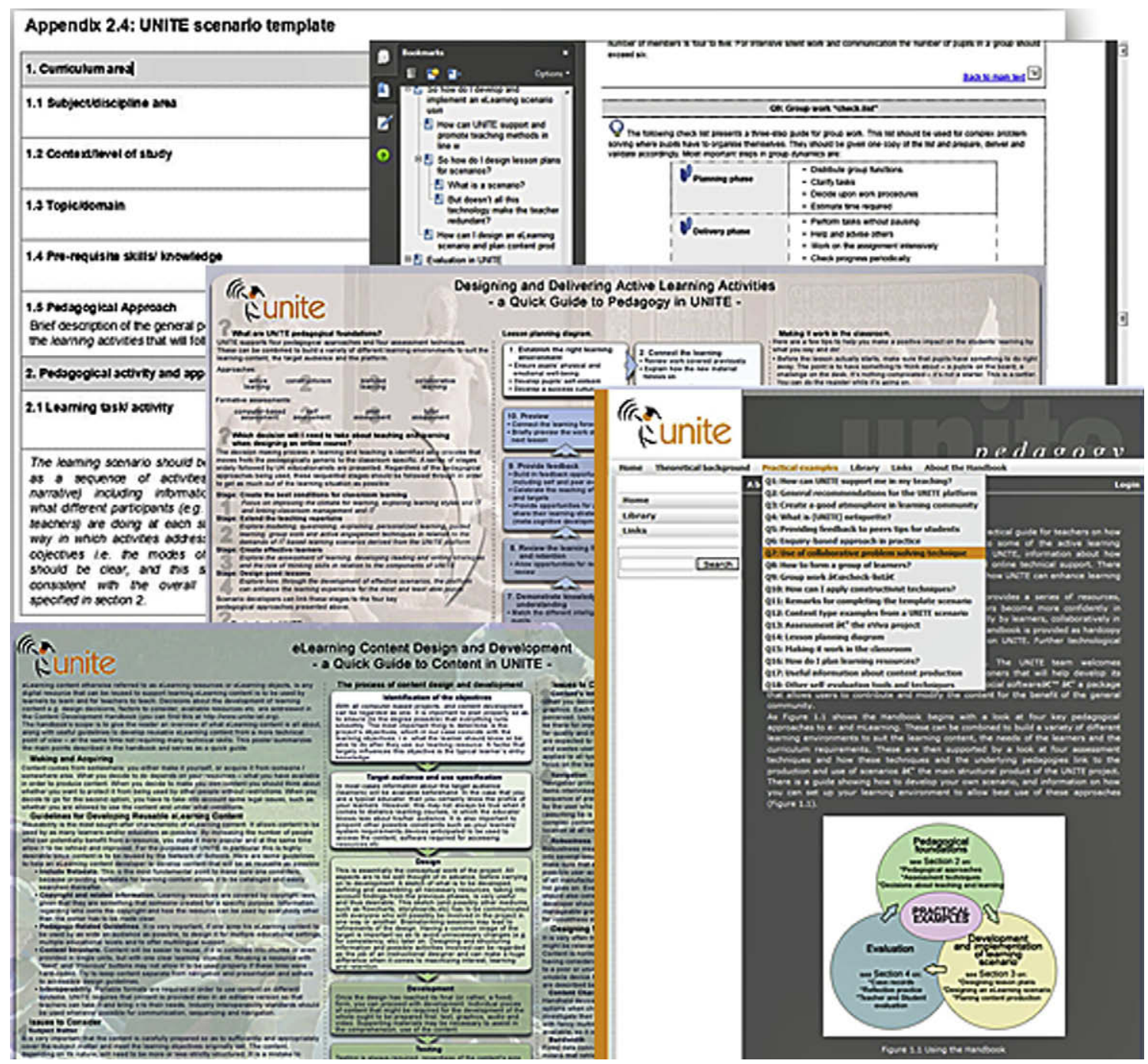

Fig. 4. Collage of the supporting material (clockwise, starting from top left: Scenario template, Teachers' handbook, Quick Guide to pedagogy in UNITE, online version of the Handbook, Quick Guide to content in UNITE).

The platform has two access points (Hornung et al., 2008); the learning portal and the learning management system are accessed via a web server (http://pilot.unite-ist.org), while the mobile devices connect via a dial-in server.

UNITE has different modules for the management of workspaces, tasks units, tasks, task submissions, evaluations and comments. It has also Trace Viewer, Gradebook and Agenda modules. Communication-related operations are covered by Chatrooms, Journals, Private messages, Announcements, Events, Forums, topics and replies, as well as the sending and receiving of SMS and MMS via the UNITE platform. Content-related operations include working with InfoPool, Quizzes, Search tool and others along with three different authoring tools: Course Editor, PPC Author and HTML Editor. There are also modules for SMS quizzes and mediaBoard contents. Some of the listed and most important features of the platform are elaborated further hers based on Kouloumbis et al. (2007) and Lu et al. (2006).

\subsubsection{User's area}

The users' area is a personal space (i.e. the virtual desktop of each user), incorporating the users' personal page (with their personal information), personal notes, their journal, messaging environment, their agenda, their allocated tasks, their personal resource area (InfoPool), and the list of the workspaces of which they are members.

\subsubsection{InfoPool}

The repository InfoPool is a "container" for all e-Learning content. It is integrated/available in the public area, user's area and workspace area. The InfoPool Viewer provides the common content management facilities to manage the contents of the platform. The course editor, the course viewer and the metadata editor are integrated to support SCORM-compliant reuse and the editing of the course and its metadata. The reusability of content in InfoPool is enabled through metadata, and the feature to edit this data using the metadata editor, a tool which is accessible through a appropriate link for every content item.

\subsubsection{Course Editor and Course Viewer}

By using the icon "create course" in the InfoPool toolbar, the authorized user can create a new course. After the course has been created, stored and displayed in the list of contents, the user can edit the course by using the "edit course" button from the "options" menu. Every 
listed course in the InfoPool viewer is associated with the Course Viewer. By selecting the course, the Course Viewer is loaded displaying the course and its navigation tools.

\subsection{4. mediaBoard}

The mediaBoard is a virtual "place" (on a web site) where students and tutors can set up an image or map as the front page of their web site, as well as send text, pictures and audio messages to different locations on the image or map. One use for this can be to set up live events. For example, students can set tasks individually or in teams, and send them in text and picture messages to prove they have been accomplished (e.g. find a specific building and take a picture of it to show where they are). A number of potential applications for this technology have emerged as a result of extensive experimentation, demonstrations and discussions with teachers and students: for example collecting and submitting evidence for vocational or other qualifications, supporting people in work experience placements, and field work and active learning in schools.

mediaBoard is fully integrated into the platform. It shares files (text, image, audio, and alike) with the system's repository Infopool. Users collaboratively interact with the mediaBoard, and upload or download their latest assets.

\subsubsection{SMS quizzes and SMS quiz engine}

Text messaging is the simplest of all the technologies, and interactive learning activities can be devised with very basic equipment. All mobile phones, including the cheapest, most basic models, can send and receive text messages, so this is so far the most widespread and used technology. Activities which require students to send messages can be of two types: learners interacting with their tutor (e.g. for extra hints, reminders, revision tips or homework questions in between classes) and learners interacting with a computer that sends automated replies.

In addition to students using SMS quizzes, tutors are given the opportunity to develop their own SMS quizzes, adapting the quiz to the context of their individual subjects. Tutors create up to five multiple-choice questions. These can be printed out, written on a whiteboard or published on the platform. Students can then text in their answers from any mobile phone. The SMS engine will track the answers and send an instant feedback message from the tutor to the mobile phone.

\subsubsection{Flash games and authoring tools}

Handheld devices can also be used to play various games and quizzes that are Flash-based and can be run on Pocket PCs. Learners can access the quizzes from the portal pages of their Pocket PCs. The games comprise familiar games, such as the Snap game, the Pairs game and other plain multiple-choice questions, "jazzed-up" by use of little flash movies. They have proven very successful for testing knowledge learnt in class or for teaching basic literacy and numeracy. In addition to these tools tutors are also provided with an "authoring engine", so that they can create their own Snap, Pairs or multiple-choice game, based on the content of their classes.

Tutors start by creating a "module" and then filling it with "activities". They can then edit and re-sequence the activities until they are happy with a module before "building" it - packaging it up and installing it on a mobile device. The student can view the materials using MyLearning player, which the authoring tool installs automatically when teacher "builds" a module on Pocket PC. MyLearning player supports many different formats of learning materials and tracks a learner's journey through them. More than one learner can use the same Pocket PC and the quizzes can be played offline as well.

Fig. 5 shows several snapshots of the UNITE user interface, and more specifically it shows Metadata Editor, Course Editor, mediaBoard image, InfoPool, Course Viewer, and Tasks modules from one workspace (created for the course "Wonderful world of inventions").

\subsection{Professional development of teachers}

In order to familiarise the teachers with the PF and its implementation through the use of the resource materials, several workshop and training sessions on the international and national levels were planned and delivered. This was to ensure that learning scenarios were consistent with the constructivist approach of the UNITE pedagogy with an emphasis on active learning, collaboration and reflection.

Firstly, partners from the collaborating institutions were trained in a "train-the-trainer" manner so that they would be able to pass on the UNITE concepts to the teachers. Following this the "trainers" briefed the teachers about the subject matter and the teachers were invited to an international training event. Here, various introductory activities (e.g. finding keywords and their definitions) were followed by an activity in which the participants/teachers had to think about how different situations could be exemplified through learning scenarios. They were asked to reflect on a particular teaching/learning episode and to think about whether they could use any of the UNITE definitions to describe what they had just experienced. Following this international event, two or more local training workshops in each participating country were held for other teachers by the partners and the teachers who participated in the first training phase. Also, a number of meetings were held where teachers discussed the design and development of their scenario with the project partners. There was continuous communication both in regular face-to-face and online meetings throughout the planning phase as well as during the implementation of the said scenarios (Ćukušić, Granić, Mifsud, \& Zammit, 2008).

\subsection{Platform preparation and its use}

The implementation of the scenarios was centrally coordinated but differed from country to country and from school to school. Some quantitative characteristics of the network of schools illustrate this. A total of fourteen schools from ten countries (Bulgaria, Croatia, Cyprus, United Kingdom, Germany, Greece, Latvia, Lithuania, Malta and Slovenia) used the platform. This involved 46 teachers and 512 students (aged 13-19 years). The learning activities from the scenario plans were realised in 26 classes (both in and out of the classroom). The average time spent by each teacher on scenario implementation is $42 \mathrm{~h}$ (Limanauskiene, Stuikys, \& Sitikovs, 2008). This is even more if we include also the time spent on scenario planning. During this time teachers prepared the platform, developed the content and/or reused it, consulted with the partner (if necessary) and carried out the envisaged field-work, home work and/or class work. Teachers could also communicate with each other using the forum on the platform. Partners submitted a weekly progress report on the work carried out with 


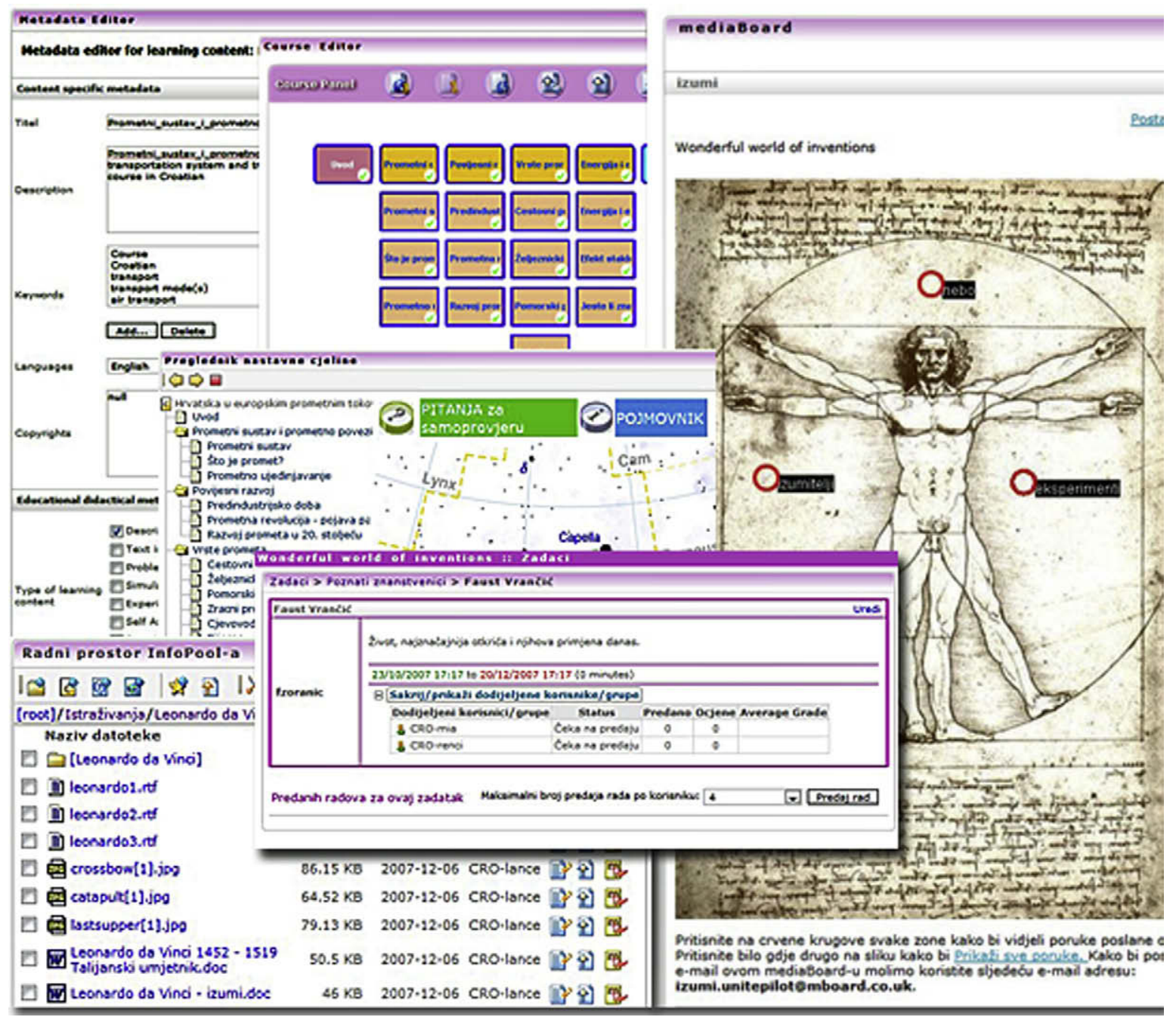

Fig. 5. Snapshots of the user interface of the UNITE system (clockwise, starting from top left: Metadata Editor, Course Editor, mediaBoard image, InfoPool, Course Viewer, Tasks).

the schools. This aided ongoing reflection and ensured consistency in the way the PF was being implemented through a scenario-based approach. There were 15 scenarios in the first phase of the implementation and 21 scenarios in the second phase.

To exemplify this implementation, a case of the realisation of a scenario in a Croatian school is provided in (Hornung et al., 2008). A team of five people was formed in the Spinut School consisting of the school headmaster, the pedagogical advisor and three subject teachers. Support in terms of organizational and technical assistance was provided by the University of Split (UoS). After implementing two scenarios with older students (13 and 14 years-old), the third scenario was intended for younger students also (11 and 12 years-old) to stimulate their interest in science and technology. An elective course entitled "Wonderful world of inventions" for gifted students was developed in order to increase the students' level of motivation and to provide an enjoyable dimension to the knowledge acquisition through the learning scenario. According to the diverse areas/stages of the course, different pedagogical approaches were implemented. For example there was project work where students were encouraged to take a more active role as researchers, and to come up with their own sketches and designs (of a parachute, a plane or similar). Subsequently, students tried out their designs in practice and actually learnt by doing. There were elements of exploratory learning, with cooperative learning in groups, with some pair work. Students were also encouraged to work/learn alone as individuals. The teacher acted mostly as the students' mentor and not as an imparter of knowledge. Field-work, numerous outside school visits and workshops provided added value to this scenario and an opportunity for students to learn astrology, robotics and science in general in a real-life environment(s). The repository, communication tools, mobile learning capabilities, notes, journals and similar functionalities of the UNITE system (see Fig. 5 for some snapshots of these functionalities) were of great relevance as students were able to track their progress, update their portfolio, reflect, explore and discuss. In this way, every student was provided with the opportunity to express her/himself, to experiment and to learn. The "Wonderful world of inventions" scenario is provided in the appendix of this paper.

\section{Pedagogical framework validation}

The validation phase of the PF implementation comprised three different activities focusing mainly on the scenario evaluation methodologies and users' feedback, both that of teachers and students (Ćukušić et al., 2008). The quality of the scenarios was controlled by partners with pedagogical expertise in the scenario planning phase. Then the relevant feedback from users summarized in the "expert summaries" 
was analysed after the scenario activities took place and areas for improvement were suggested. Finally the pedagogical dimension of fourteen scenarios implemented in the second implementation phase was evaluated.

\subsection{Quality control of the scenarios}

Scenarios had to be as detailed and as descriptive as possible so they could be reused and evaluated properly. There were instances when teachers referred to the tools they used without explaining how these tools were integrated in their scenario and what were their objectives for doing so. In order to avoid this, it was decided that an internal evaluation mechanism was to be adopted is before the final delivery and implementation of the scenarios. Four "pedagogical" experts, three "technological" experts and an expert responsible for the quality of the planned content reviewed the first version of the scenarios and commented on them according to their respective expertise within the consortium. Several criteria (e.g. level of details, scenario length, type of preferred learning activities and platform modules etc.) for every aspect of the scenario (pedagogy, technology and content) were agreed upon and taken into consideration. Based on the received feedback, teachers delivered new versions of their scenario(s) which they eventually implemented in real school settings.

The pedagogical feedback encouraged scenario developers (i.e. teachers) in the main to:

- reflect on the pedagogical decisions that have been made throughout the scenario planning and implementation and the reasons which led to such decisions,

- provide more detail when describing the activities and when identifying the objectives and the assessment techniques and

- consider suggestions about how to improve and enhance the scenario and its implementation.

This was done to encourage teachers to reflect on how the use of new technologies enhances the learning experience and adds value to it rather than simply being introduced for the sheer novelty of the medium. Furthermore, in most cases not enough detail was provided for an independent reader to make complete sense of what was intended. Teachers were then asked to describe activities in more detail and to mention any preparatory work such as how they had introduced the UNITE platform to their class. In terms of planning and design teachers required more guidance when creating their own e-Learning scenarios as opposed to when reusing some of the learning scenario templates. Recommendations mainly encouraged teachers to design more student-centred activities in line with their learning objectives. Once again this suggests a paradigm shift in the planning and delivery of lessons making the most of UNITE's tools and collaboration potential.

The following are some examples from the comments of the experts:

“... If they are all going to work at the Computer lab i.e. they are physically present then why are they going to use the chat and forum to communicate? What's the value-add of the platform here?"

“... More detail needed. Please explain. How is this a resource for your students? Who are the 'senior students'?"

“... How will this be measured? What are the criteria? Can you give more details in terms of educational aims that will demonstrate that learning did indeed take place?"

“... (Peer assessment) Should be noted within learning activities. What are the criteria for peer-assessment? Given by the teacher or set by students? Are students used to this kind of assessment? Will they be able to come up with a set of criteria?"

“... A general comment from the pedagogical perspective. Try to think how activities can be more student-centred and perhaps objectives should be more clear, coherent and more focused. I find this very teacher-centred so far. Can the teacher guide the students to find some of these on their own rather than showing them everything. They can better own the process if they find it themselves."

Most scenarios were fairly consistent with the template and no major differences were observed in how teachers from different countries planned and delivered their scenarios. The same issues emerged during the second validation phase as from the first one, mainly owing to the fact that teachers were now encouraged to develop their own scenarios. However in this second validation phase it was noted that teachers needed more guidance in terms of planning and designing their learning activities when creating their own scenarios. Some seemed to struggle with setting clear learning objectives on which learning activities and assessment can be designed. It was evident that some teachers found it rather hard to conduct learner-centred activities using e- and m-Learning resources. A number of them were still coming to grips with the new technologies.

\subsection{Validation of the pedagogical processes}

The principal method for the qualitative evaluation of the pedagogical processes was the "case record". A case record within the framework of the project stands for a collection of data about a "case" i.e. all the video/audio clips, documents of different kinds and evaluative notes/comments of the scenario (Kellner et al., 2008); see (Walker, 2002) and (Groundwater Smith \& Walker, 2000) for more information about case records and its definition. Here, the "learning scenario" is the "case". At least one detailed case record was produced per scenario following a common format but offering a significant degree of flexibility. The starting point for producing a good case record was the successful completion of the learning scenario template and that is why (Kellner et al., 2008) state that "it is possible to describe the UNITE model for validation as a marriage between case record methodology and scenario based design".

Using a web-based tool it was possible to evaluate the scenario in terms of its integrity and coherence since the tool provided links to information about learning objectives, assessment strategies and resources for each learning activity. In addition to these planned activities, case records contained a rich selection of material (real evidence of learning and possible alterations) and were open to multiple interpretations since the open-ended structure of the case record required participants (partners and teachers) to focus on those aspects of their scenario where it could be shown that the platform genuinely "added value" to teaching and learning. By inviting participants to highlight the parts of the scenario that potentially provided "added value" the central question - i.e. has UNITE met its overall objectives (Kellner et al., 2008) was addressed in a direct manner. The "teacher evaluation" is one of four formal evaluations within the case record. The other two evaluations, the "student" and "other" (for school administration, other teachers and the rest) follow a similar format. The fourth evaluation, the "Expert Summary" is a crucial document within the case record since it was completed by a member of the UNITE consortium 
who was familiar with the scenario implementation and who was asked to write a commentary (summarizing the main points made in the student and teacher evaluations) and to produce a scored list of criteria against which "expert" judgments were made.

The purpose of the entire exercise was to focus on key pedagogical principles (collaboration, personalization, active learning and the like) in relation to which the UNITE project should be judged. The analysis was based on 15 expert summaries in the 1 st phase of the evaluation and 21 expert summaries in the second phase (or case records produced by project partners) revealed the following (statements are based on users' feedback exclusively).

\subsubsection{Autonomous learning}

There is evidence that the system supports both autonomous and collaborative learning. It provides opportunities for blended learning through the mixing of work on the platform and group work. The platform can be used as a content repository (accessible from everywhere at any time) and as a means of communication both synchronous (Chatroom functionality) and asynchronous (Forum, mediaBoard and private messages). Students used Internet access, e-mails and mobile phones to contact each other and to keep in touch with their teachers and their classmates when on a school trip. Students can study autonomously materials stored in the InfoPool and then work in groups. UNITE allows for a mixture of individual and group work activities like reading, writing, doing quizzes, and the carrying out of experiments.

In some cases students had an opportunity to produce new e-Learning content (for example, a web site) which can be used over and over again by other students and teachers. In some scenarios the students used mobile devices (mobile phones, digital cameras, pocket PCs and laptops) to collect information.

\subsubsection{Innovation}

The innovation that the system brings to the school "is related to the use of technology for learning, use of a controlled media for learning (the platform) where students can pick out/add the content themselves with the teacher's assistance. The content is available in one, "safe" environment and in different forms (photos, movies and a like)". Another innovative aspect is that related to teacher availability anytime via chat, forum, and messages. Furthermore the process is more transparent for the parents. There is the possibility of self-assessment based on the evaluation of students" own activities and other students' activities.

In an autonomous manner the students can search for and find additional materials which enhance the learning content. The students are expected to work in teams which stimulate their creativity and competition skills. System empowers students to assume a larger role in their own learning. The innovative potential of the technology lies mainly in the e- and m- Learning interface through 24/7 hand-held computer use that can be integrated in the larger UNITE system. A feature which both teachers and students found to be relevant is the mediaBoard as it can be used in creative ways.

\subsubsection{Individualisation}

Every student should be able to define his/her own speed of learning. UNITE offers the option of individual learning. It is possible to individualise tasks for each student, adapted to their respective level of knowledge, using the platform. It allows access to learning resources from home.

According to the teachers, the system communication technologies were very useful in supporting team work and in stimulating individual initiatives. The implemented scenarios and the system tools gave teachers the opportunity to provide individual attention to each student. Each student could accomplish a specific task, relating to the accumulation of content. In some scenarios, individual problem-solving tasks were assigned to the students. The individual learning tasks were supported by the chat with experts. Individual tasks were assigned to students according to their talents, preferences and skills, with the view to maintaining a balance between collaborative and individual tasks. Notwithstanding, some students claimed that it was difficult to keep the motivation without the direct mentoring of the teacher and communication with classmates is sometimes missing. The platform allows the teacher increased opportunities for tracking better individual and group performance. It allows also the teacher to follow the individual learning path of each student. More advanced students are able to proceed with more advanced tasks while the teacher is checking their submitted ones. In this way the lesson is never boring for students.

\subsubsection{Efficiency}

The UNITE system becomes efficient in multi-shift usage and embedding in the day-to-day teaching process. In specific areas in-depth work was possible, especially if students controlled and assessed their work autonomously. Control by the teacher was reduced in aid of the increased autonomy of the students. In some learning activities, classroom processes were speeded up due to the technology. Students shared a common workspace and all educational material was available to all classrooms. Students had the opportunity through chat and forum to exchange ideas.

\subsubsection{Effectiveness}

Most of the teachers claimed that UNITE had helped them to achieve the pedagogical objectives they had set for their students. For example student groups worked together, formulated the quiz questions, and uploaded them to the tasks section so that all students had access to them. They could edit, change or update them. This functionality was significant for the accomplishment of the group tasks. Furthermore students can use the material prepared by other students. For example, they can try out the experiments other students performed using the guidance from InfoPool.

\subsection{Evaluation of the pedagogical dimensions of the learning scenarios}

In order to demonstrate how UNITE enhances the learning experience, we present the results of an analysis of the pedagogical dimensions of the learning scenarios according to Reeves' (1994) methodology. The fourteen pedagogical dimensions of computer-based education (CBE) proposed by Reeves are concerned with those aspects of the design and implementation of the system under study that affect directly the learning process. They refer to the capabilities of the system or the scenario to initiate powerful instructional interactions, 
monitor learner progress, empower effective teachers, accommodate individual differences, or promote cooperative learning. The fourteen pedagogical dimensions are presented in Table 2.

Reeves's multidimensional model allows categorization of the different programs or e-Learning systems according to different aspects. It is possible to compare one form of the system or a programme to another, or even to compare different implementations of the same system or educational programme. While the above-mentioned dimensions represent a framework for comparative analysis, the table can be used for planning purposes also, as part of the deliberations on the future design of a learning scenario or an educational programme. Earle (2002), based on his own experience, concluded that these fourteen aspects provide an extremely simple way to conceptualize possible outcomes of educational programs. The author himself, Reeves, explains the need for evaluation of outcomes in the following manner: the results of evaluations of educational programs are often inadequate because they are in the form of descriptive statements, while the reviewers themselves often find the programs incomparable. Reeves's methodology has been used on several occasions (Boer \& Collis, 2002; Leonard, 2003; Quinton, Dreher, Fisher, \& Houghton, 2005), and the dimensions as such represent the range of pedagogical criteria that have been used to compare different forms of computer-supported educational processes. The original number of dimensions (fourteen) has been both extended and shortened. For the purpose of this research, the original methodology was used since it fully covers all aspects of an average system (users, methodologies and technologies) for e-Learning. It is possible to select any position on the continuum for each of the dimensions and the number of potential permutations of the outcomes is practically unlimited.

The scenarios implemented in the last iteration (fourteen of them) were rated by teachers themselves (self evaluation) and four expert pedagogical evaluators who observed firsthand the implementation of the scenarios in schools. We reckoned that these scenarios would

Table 2

Pedagogical dimensions of CBE (applied to a learning scenario) (Reeves, 1994).

\begin{tabular}{|c|c|c|}
\hline $\begin{array}{l}\text { Pedagogical dimensions of computer-based education } \\
\text { 1. Epistemology }\end{array}$ & Objectivism & Constructivism \\
\hline 2. Pedagogical philosophy & Instructivist & Constructivist \\
\hline 3. Underlying psychology & Behavioural & Cognitive \\
\hline 4. Goal orientation & Sharply-focused & Unfocused \\
\hline 5. Experiential value & Abstract & Concrete \\
\hline 6. Teacher role & Didactic & Facilitative \\
\hline 7. Program flexibility & Teacher-Proof & Easily Modifiable \\
\hline 8. Value of errors & Errorless Learning & Learning from Experience \\
\hline 9. Motivation & Extrinsic & Intrinsic \\
\hline 10. Accommodation of individual differences & Non-existent & Multi-faceted \\
\hline 11. Learner control & Non-existent & Unrestricted \\
\hline 12. User activity & Mathemagenic & Generative \\
\hline 13. Cooperative learning & Unsupported & Integral \\
\hline 14. Cultural sensitivity & Non-existent & Integral \\
\hline
\end{tabular}

Table 3

Evaluation of the learning outcomes per dimensions and scenarios (as rated by the experts).

\begin{tabular}{|c|c|c|c|c|c|c|c|c|c|c|c|c|c|c|c|}
\hline Scenario title & E-1 & $\mathrm{E}-2$ & E-3 & E-4 & $\mathrm{E}-5$ & $\mathrm{E}-6$ & $\mathrm{E}-7$ & $\mathrm{E}-8$ & E-9 & $\mathrm{E}-10$ & $\mathrm{E}-11$ & $\mathrm{E}-12$ & $\mathrm{E}-13$ & $\mathrm{E}-14$ & Scenario mark \\
\hline The human being: nutrition and digestion & 6 & 11 & 11 & 10 & 4.8 & 11 & 6.8 & 11 & 6.5 & 2.5 & 4.1 & 3.9 & 3.6 & 6.5 & 7.05 \\
\hline Ecosystem & 9.7 & 10 & 9.7 & 10.8 & 11.6 & 11.2 & 9.8 & 10.2 & 10.2 & 9.2 & 8.7 & 12.4 & 10.5 & 9.3 & 10.24 \\
\hline Investigating global warming & 8.6 & 7.3 & 8.7 & 8.2 & 8.2 & 7.6 & 9.6 & 9.2 & 7.8 & 7 & 7 & 10 & 9.5 & 6.7 & 8.24 \\
\hline Historical heritage of Trbovlje & 8.2 & 8.8 & 8.7 & 9.5 & 8.6 & 8 & 6.3 & 8 & 8.3 & 9.3 & 8 & 8.7 & 12 & 1 & 8.10 \\
\hline Traffic Survey & 8.8 & 7.5 & 9.1 & 8.4 & 8 & 7.7 & 9.7 & 10.3 & 7.7 & 7 & 6.8 & 10.2 & 9.6 & 7 & 8.41 \\
\hline Environmental Studies & 9.7 & 10.2 & 8.7 & 10.3 & 11.6 & 10.5 & 9 & 11.6 & 9 & 7 & 9.6 & 11.2 & 9 & 7 & 9.60 \\
\hline Wied Ghollieqa fieldwork & 10.5 & 6.7 & 9 & 5.6 & 10.5 & 6.6 & 7.9 & 9.7 & 12 & 7.6 & 6.8 & 9.6 & 8.2 & 7 & 8.41 \\
\hline Ancient Agora of Athens & 13 & 13 & 12.9 & 12.6 & 12.5 & 12.5 & 10.6 & 12.5 & 9.7 & 10.8 & 8.5 & 8.2 & 11.2 & 1 & 10.64 \\
\hline Creating databases & 3 & 3 & 3.8 & 4 & 11.2 & 11.2 & 7.2 & 3 & 7 & 2.4 & 4.5 & 11.3 & 3.6 & 7.2 & 5.89 \\
\hline New ICTs - visiting BAIT Expo 2007 & 7.8 & 7.6 & 7.7 & 8.5 & 12 & 7.8 & 7.8 & 10.8 & 8 & 9 & 7 & 13 & 10.2 & 7.2 & 8.89 \\
\hline ICT in education - guide of Trbovlje city & 8.4 & 8.2 & 8.4 & 8.2 & 7.8 & 8.3 & 6.8 & 8 & 8.8 & 7 & 8 & 8.4 & 12.4 & 1 & 7.84 \\
\hline Youth crime & 11.4 & 11.4 & 11.4 & 10 & 5 & 11.4 & 7 & 3 & 7 & 2.4 & 4.5 & 4.2 & 3.8 & 7 & 7.11 \\
\hline Teenage well-being & 12.8 & 13 & 12 & 13 & 13 & 12.7 & 12 & 12.4 & 12 & 12.2 & 12 & 12.8 & 12.2 & 12.6 & 12.48 \\
\hline Wonderful world of inventions & 13.4 & 13.2 & 13.2 & 12.8 & 13.2 & 13 & 11.6 & 13 & 12.5 & 12 & 13.3 & 12.6 & 12.6 & 8.6 & 12.50 \\
\hline Traveling & 10.1 & 8.9 & 4 & 4.1 & 10.8 & 8.9 & 6.8 & 11.3 & 7.1 & 2.1 & 3.7 & 3.6 & 4.1 & 6.7 & 6.59 \\
\hline Average & 9.43 & 9.32 & 9.22 & 9.07 & 9.92 & 9.89 & 8.59 & 9.60 & 8.91 & 7.17 & 7.50 & 9.34 & 8.83 & 6.39 & 8.80 \\
\hline
\end{tabular}


exploit and articulate the concepts better than the ones implemented earlier since the users had had time to familiarise themselves with the technological and pedagogical underpinnings of the project. All the four experts were researchers from the field of e-Learning, and their task within the project was to support the teachers while developing their own scenarios (not the ones they in turn evaluated). This ensured that they possessed the necessary knowledge and objectivity to rate the level of the dimensions of the several scenarios. The experts were very familiar with the scenarios they were asked to evaluate as they had monitored the quality control of the scenarios prior to their implementation in the two iterations.

The evaluation was performed using a form with a sliding scale for every dimension of the scenarios being studied (E1-E14). The outcome of each dimension was estimated qualitatively (sliding scale) so as not to burden the user numerical scale. While analysing the results, the qualitative estimates were converted into numerical measurements as distances of the marked positions on the line (in centimetres), from 0 to 14 (see Table 3).

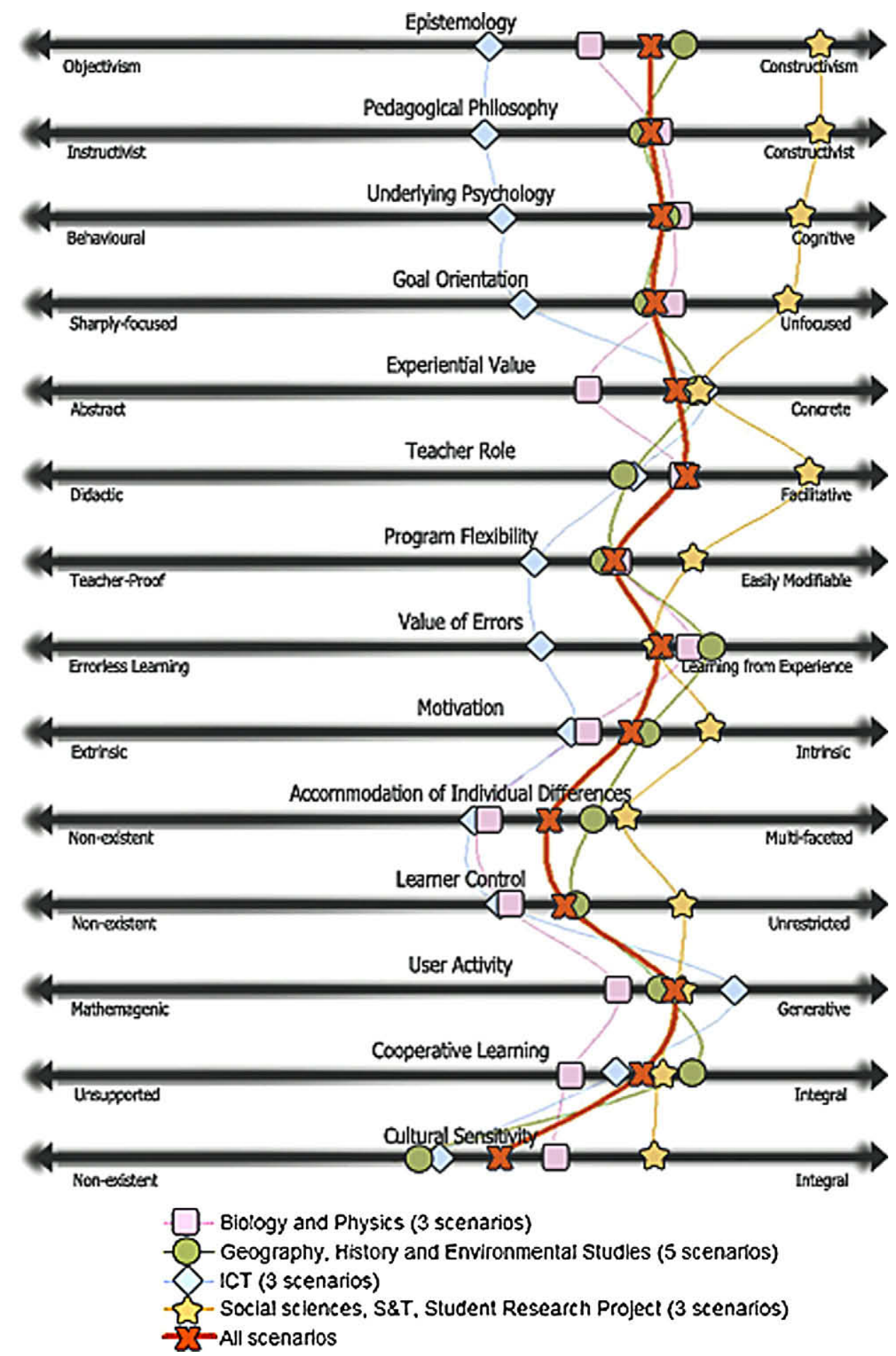

Fig. 6. Pedagogical dimensions (Reeves, 1994) of all the scenarios compared to the scenario groupings. 
On average, with regard to the epistemology the experts believed that the scenarios tend to constructivist theory of knowledge (9.43). From the aspect of educational principles the scenarios tended largely to constructivist theory of knowledge as well (9.32), and from the point of psychological basis to cognitive psychology (9.22). From the aspect of objectives orientation experts believed, as opposed to teachers, that scenarios tended towards less focused goals and objectives of the scenarios that are not sufficiently clear (9.07). From the aspect of the value of practical experience experts believed that the scenarios tended to concrete, practical experiences (9.92) and as for the aspect of the role of teacher towards mentoring (9.89). From the aspect of flexibility, scenarios were, in the opinion of experts, flexible (8.59), while considering the value of errors they promoted an experimental, research-based teaching methodology of "trial and error" (9.60). With regard to the source of motivation, scenarios encouraged intrinsic motivation (8.91), and in the case of individual differences, scenarios were relatively neutral in encouraging individuality (7.17). With regard to the level of control, experts believed that the scenarios provided a certain level of control (7.50). Where user activity was concerned, experts believed that the scenarios encouraged students to generate their own materials for learning (9.34). In the case of cooperative learning, scenarios encouraged students to engage in cooperative learning (8.83) while with regard to cultural sensitivity scenarios had no effect on increasing cultural sensitivity within the scenarios of e-Learning (6.39).

An evaluation of the scenarios based on Reeves' (1994) pedagogical dimensions revealed that UNITE is based on constructivist and cognitive foundations. The mean scores of all the fourteen scenarios and scenario groupings on pedagogical dimensions were plotted as trend lines (see Fig. 6). There are four scenario groupings: (i) Biology and Physics (B\&P, 3 scenarios); (ii) Geography, History and Environmental Studies (G,H\&ES, 5 scenarios); (iii) ICT (3 scenarios) and (iv) Social Sciences and Student Research Project (SS, 3 scenarios). This analysis reveals that when considering the overall pedagogical dimensions of all scenarios, it is the SS scenario grouping which follows most closely the overall trend. This is followed to a lesser degree by the B\&P and G,H\&ES scenario group. It is the grouping of ICT scenarios which is the least representative of the overall trend of pedagogical dimensions.

Overall, students were encouraged to learn from concrete experiences and were offered intrinsic motivation. Teachers were integral facilitators in implementing the scenarios, and they were encouraged to modify it according to their local needs and to meet individual differences. Collaborative learning was strongly supported by the scenarios.

\section{Summary and discussion}

The processes outlined in this case study illustrate the way in which a pedagogical framework (PF) was designed, implemented and validated by a Europe-wide network of education experts and secondary schools. Major concerns were the specific needs of the national educational systems of the countries involved and respect for the current pedagogical practices implemented in the national curricula of these countries. The PF analyses the process of teachers' pedagogical adoption of e- and m-Learning. It makes the case for a wider pedagogical and analytical framework that takes into account cultural factors and the regulatory frameworks and policies of national education systems.

Teachers and students take on board new pedagogical practices by attempting to find a "fit" with existing ones. Over time, through constant adoption in the classroom situation, these are integrated into their current educational practices. This process is determined by school contexts and organizational structures, and established mechanisms of control in schools, such as national curricula and assessment systems. Teachers must be aware of contextual factors that directly or indirectly affect the implementation of the framework in order to be in a better position to negotiate curricular, syllabus and organizational issues like timetabling. However it is not clear to what extent and how soon the transformation of pedagogical practices through ICT can be achieved. Cartwright and Hammond (2007) insist that "the notion that all schools are somewhere along a path of ICT adoption that will ultimately lead to a transformation in teaching and learning is unrealistic" and that the effective integration of technology by teachers into the teaching and learning process is "a complex and long-term enterprise" which requires considerable support (Cartwright and Hammond, 2007, p. 405).

It is difficult to determine direct causality between the features of the pedagogical framework and their implementation in the classroom. The PF was designed as a conceptual and operational tool for reflecting on and implementing the educational practices surrounding the use of e- and m-Learning in secondary schools. It is not intended to provide a precise measurement of those practices. Although it focuses on educational practices, it does not attempt to explain the underlying factors on which those practices are based. There is no attempt to identify causal relationships between underpinning variables and the concomitant practice. However, by considering the various implementation and evaluation phases of the PF, it is possible to make some tentative interpretations of the results. The results of this study indicate that the teachers' implementation of the pedagogical framework developed into increased mastery in the school context. Teachers from the second validation phase became more confident in their application of the framework principles and demonstrated a more positive evaluation of the outcomes. As a result, they became more aware of the opportunities that the framework can offer in their teaching at the secondary school level.

\section{Conclusions}

There is some evidence in this study of e-/m-Learning contributing to improved learning by students. Qualitative validation of the implementation results was based on users' feedback. The analysis revealed that the system supports both autonomous and collaborative learning. It provides opportunities for blended learning through platform and group work in face-to-face settings. Also students can define their own speed of learning and are empowered to assume a larger role in their own learning. Furthermore, in order to demonstrate how UNITE enhances the learning experience, the pedagogical dimensions of the learning scenarios were analysed. The pedagogical dimensions refer to the capabilities of the system or the scenario to initiate powerful instructional interactions, monitor learner progress, empower effective teachers, accommodate individual differences, promote cooperative learning and so on. This analysis showed that the system is based on constructivist and cognitive foundations. Students are encouraged to learn from concrete experiences and are offered intrinsic motivation. Teachers are integral facilitators in implementing the scenarios, and they are encouraged to modify it according to their local needs and to meet individual differences. Collaborative learning is strongly supported by the scenarios. However, it is clear that these benefits are dependent on the way in which the teacher selects and organizes the ICT resources, and how this use is integrated into the learning scenarios in the classroom and beyond. The crucial element remains the teachers and their pedagogical approaches, hence the need for a well-developed pedagogical framework. 
If e- and m-Learning are to have a positive effect on students' learning, then the technology needs to support the underlying instructional approaches. The effective use of new technologies requires an organized pedagogical structure so that students can develop their own meaningful representations of knowledge using e-/m-Learning. In order to facilitate interactivity teachers require a new approach to pedagogy. They need to adopt proactive strategies in order to facilitate learning. They can support progress in learning by providing structured and focused classroom tasks.

Major features of the effective use of e-/m-Learning are the planning, preparation, implementation and evaluation of learning scenarios. The pedagogical style adopted by the teacher, the learning objectives and the selection of activities and resources need to be also wellorchestrated. Teachers require significant time and resources to extend their repertoire of uses of ICT in education in a significant and effective manner. The pedagogical foundations for ICT use in the classroom need to be solid enough to enable effective learning but flexible enough to allow for the needs of different learners. As with other educational intervention programmes, perhaps the greatest challenge for UNITE is that of bringing about a culture change, a change towards increased levels of efficiency and effectiveness of the teaching and learning processes.

\section{Acknowledgments}

This work has been carried out within the project UNITE 026964: Unified e-Learning environment for the school, partially supported by the European Community under the Information Society Technologies (IST) priority of the 6th Framework Programme for R\&D. The research has also been supported within the Project 177-0361994-1998 Usability and Adaptivity of Interfaces for Intelligent Authoring Shells funded by the Ministry of Science, Education and Sports Technology of the Republic of Croatia.

\section{Appendix. Elective course scenario “Wonderful world of inventions”, delivered by Spinut School, Croatia}

The elective course titled "Wonderful world of inventions" is guided/mentored by school's pedagogue. She is not a teacher in a classical sense of the word. Course (programme) curriculum is solely her idea. The course lasts throughout the whole school year so for now it is possible to present the detailed planning for the activities that already took place and provide only an overview of the planned ones. The last steps of the scenario (activities No. 17, 18 and 19) could/should be separate scenarios with further insight into how will the activities be organized step-by-step. What we wanted to present here is the framework of the activities that can be built upon. Field trips mentioned here are already scheduled but there may be some additional ones.

UNITE will be/is used mostly as a repository of the learning material (either provided by the mentor or collected by students as a part of their research assignment) as well as an irreplaceable communication platform. Both synchronous and asynchronous communication and collaboration functionalities of the system are important for this scenario since the course is attended by a very heterogeneous group of students. They attend their regular courses in different times of day; they go to different classes etc. The accent is on optional/mentored learning activities based on a sort of an "open planning". The pedagogue will change/edit her scenario plan based on the developments from the previous learning activities and the feedback received from students. There is e.g. a sort of project work where students will be encouraged to take more active role, the role of researchers and to come up with their own sketches and designs. The pedagogue will act mostly as students' mentor/facilitator and not as a teacher (this is very important). Students are also supposed to (i) comment, (ii) suggest and (iii) evaluate all of the topics suggested by the scenario and the way they learn. The scenario aims to provide the learning opportunities mainly for talented students.

\section{Appendix 1. Curriculum area}

Subject/discipline area

Context/level of study
Science and technology (S\&T). Multidiscipline area (gaining social skills, learning how to learn).

This elective/optional course aims to tackle following questions: What do we need to do to make a product from idea? Which scientists contributed to the world? What can I invent? What is a scientific approach? How to perform a scientific research? What are the steps to follow in scientific research?

Scenario is prepared for a heterogeneous group of students from 5 th to 8 th grade (11-15 years old). Its purpose is to:

- instigate interest in science

- teach students to use their senses through structured activity

- develop the skills of observation, perception and deduction

- teach the students to make structured notes and different monitoring protocols

- familiarise children with the universal scientific methods and the ways of approaching a problem

- encourage the critical attitude and the discussion and

- encourage the spirit of innovation

The pedagogue (teaching/mentoring the elective course) will initially provide a frame of activities or the contents of future classes. The areas will include: research, experiments, robotics, astronomy, innovations. All the students will participate in every activity

One part of the activities will take place regularly in school (once a week) and the other part through activities according to the dynamics of the subject. For example: (i) the exercise of sky observation will take place in agreement with the instructor of the program "The sky as a gift" (see http://nebo.znanost.org), (ii) the visit to the Astro Village on a nearby mountain - in agreement with ZTK (Association for Technical Engineering), (iii) collaboration with MedILS (Mediterranean Institute For Life Sciences) according to the availability of laboratories, (iv) individual work of students and consultations with their mentor, (v) collaboration with our UNITE partner. . 
Topic/domain $\quad$ The following topics are integrated in the scenario: Life and work of famous researchers, scientists

Pre-requisite skills/ Inventions that changed the world. Innovation and possibly the scientific work. Astronomy. Robotics knowledge Willingness to acquire new knowledge. Knowledge of English language (relative to students' age). The basics of the Internet; group work; creating PowerPoint presentations; producing posters; presentation skills.

\section{Appendix 2. Pedagogical approach}

According to different area/stage of the course different pedagogical approaches will be implemented. For example, there will be project work where students will be encouraged to take a more active role, the role of researchers and to come up with their own sketches and designs (of either a parachute, a plane or similar). Then, students will try-out their designs in practice and will actually learn-by-doing.

There will be a lot of exploratory learning, with elements of cooperative learning in groups, also some pair work. Students will be taught how to work/learn individually/independently. The pedagogue will act mostly as students' mentor/facilitator and not as a teacher (this is very important).

Field work, numerous visits and workshops will be a great value-add to this scenario and an opportunity for students to learn astrology, robotics and science in general in a real-life environment(s).

\section{Appendix 3. Learning activities}

Sometimes several activities are grouped for easier understanding. Namely, the activities related to (i) the experiments, (ii) the research on famous scientist, (iii) the exploration of scientific research methods, and (iv) "The sky as a gift" project activities contain the reference in the activity title. Other activities are either individual or relate to all of the scenario activities.

\subsection{Activity 1 - introducing the course and forming a group of students}

Activities 1 and 2 are introductory activities that tend to:

- introduce the general idea behind the course to all students in the school and

- form a highly motivated / talented group that will participate in this year's courses of "Wonderful world of inventions".

The activities take place in the school.

\begin{tabular}{|c|c|}
\hline Learning tasks/activities & $\begin{array}{l}\text { A questionnaire with several elective course descriptions (along with the Wonderful world of } \\
\text { inventions (WWI) course description) is prepared and given to every student from } 5 \text { th to } 8 \text { th grade } \\
\text { (11-15 years-old students) } \\
\text { Students choose their elective course based on their preferences (they are not required to do so) }\end{array}$ \\
\hline Learning objectives/outcome(s) & $\begin{array}{l}\text { To offer some creative activities to the students } \\
\text { To examine the students' interest for signing up for the additional activities }\end{array}$ \\
\hline Tools/resources & Elective course questionnaire \\
\hline $\begin{array}{l}\text { Assessment strategy (feedback and/ } \\
\text { or evidence) }\end{array}$ & Informal feedback/talk to students about their learning preferences \\
\hline Time allocated & $45 \mathrm{~min}$ \\
\hline
\end{tabular}

\subsection{Activity 2 - presenting the curriculum/program of the course}

The students that opted for the WWI course are gathered around and presented with the program of
the course.
The new areas of work / the topics are presented in brief and will be introduced gradually during the
year. Some of the areas are:
- the experiments (individual or pair exercises)
- research on the famous persons (pair work)
znanost.org and the Ministry of science, education and sports)
- robotics workshops (in cooperation with Faculty of Electrical Engineering, Mechanical Engineer-
ing and Naval Architecture)
- innovation work with the mentor
- project work / practical work etc.
Students are given possibility to quit the course if they do not feel able to follow the program's
dynamic. Also, they are given the opportunity to suggest the area they are interested in
To select motivated individuals and to introduce them to activities scheduled by the program
To make the class interesting, to allow every student to identify himself/herself in some of the areas
To encourage the students to express their interest, to complete the content with suggestions that
derive from their interest


Tools/resources

ment strategy (feedback and/or evidence)

Time allocated
PPT Presentation prepared by the mentor (later on uploaded to UNITE InfoPool)

Letter of motivation from Croatian Physical Society (manuscript available from the project "The sky as a gift") (will also be uploaded to UNITE InfoPool)

CD and the workbook for the students prepared by "The sky as a gift" project

Discussion

$90 \mathrm{~min}$

\subsection{Activity 3 - 1 st group meeting}

The activity takes place in a classroom.

\begin{tabular}{|c|c|}
\hline Learning tasks/activities & $\begin{array}{l}\text { Two students that had participated in MedILS' Summer School 2007: Summer science factory (http:// } \\
\text { www.medils.hr/eng) will perform three motivation experiments in front of the class. The } \\
\text { experiments are: } \\
\text { - DNA extraction } \\
\text { - Egg roentgen } \\
\text { - Experiment using a mirror }\end{array}$ \\
\hline Learning objectives/outcome(s) & To motivate the rest of the students \\
\hline & $\begin{array}{l}\text { To encourage the development of the curiosity, asking questions, research, to motivate for the } \\
\text { individual search of the experiments on the Internet }\end{array}$ \\
\hline Tools/ Resources & $\begin{array}{l}\text { Goods/materials for the experiments (blender, peas, tomatoes, ethanol, detergent, salt, eggs, candle, mirror. . ) } \\
\text { Digital camera }\end{array}$ \\
\hline $\begin{array}{l}\text { Assessment strategy (feedback } \\
\text { and/or evidence) }\end{array}$ & $\begin{array}{l}\text { Following/assisting in the experiment performance } \\
\text { Discussion }\end{array}$ \\
\hline Time allocated & $45 \mathrm{~min}$ \\
\hline
\end{tabular}

\subsection{Activity 4 - getting familiar with UNITE}

The activity takes place in UoS's ICT lab (nearby the school) and is organized in two separate sessions.

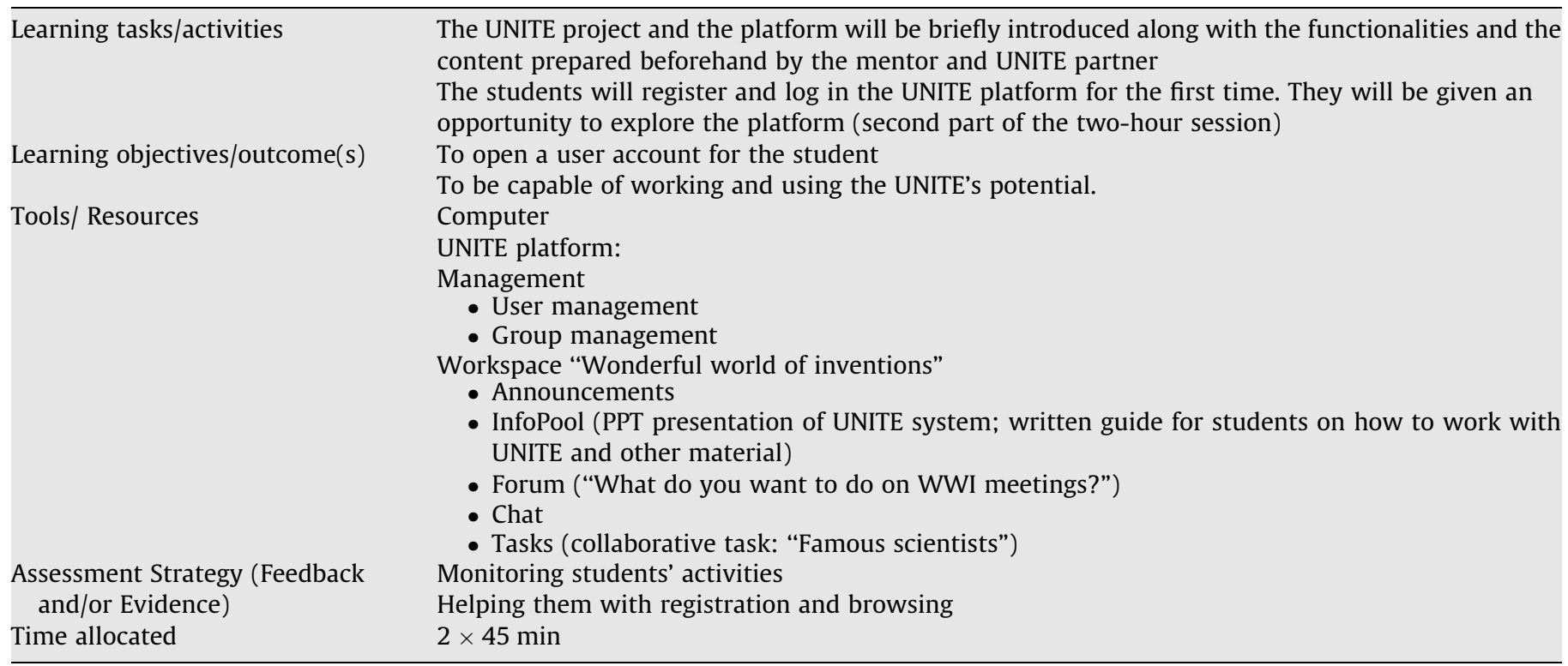

\subsection{Activity 5 - [I. Experiments]: the assignment of simple experiments}

UNITE platform is used to assign the experiment. The experiments are prepared at home.

Learning tasks/activities
The mentor prepares the written how to instructions for students. They find their assignments on the platform (as simple experiments). Pairs or groups of three choose the experiment they want to try at home and prepare the presentation to the rest of the group. Students use UNITE Chat and Messages to coordinate each other, agree which experiment they will perform, who will perform it and discuss with their mentor who will bring the material for the selected experiment and similar. Mentor tracks the log using Trace viewer as a part of his assessment strategy

Time for consultation is also arranged using UNITE (if required). Students can find, suggest and prepare any simple experiment they want (instead of the one assigned to them) 
Learning objectives/outcome(s)

Tools/ Resources

Assessment strategy (feedback and/or evidence)

Time allocated
To motivate the students for including other people (e.g. family, friends) in their learning activities The ability to work individually and to perform the experiment (presentation)

To develop certain social skills

UNITE platform:

Workspace "Wonderful world of inventions"

- Announcements

- InfoPool ("Eksperimenti" folder)

- Chat

- Messages

- Trace viewer

- Material for experiments (if required; requested from the mentor using UNITE messages functionality)

Tracking the log (Trace viewer) in UNITE

Consultations

2 weeks

\subsection{Activity 6 - [I. Experiments]: the experiment performance/presentation}

The activity takes place in a classroom.

Learning tasks/activities

Learning objectives/outcome(s)

Tools/resources

Assessment strategy (feedback and/ or evidence)

Time allocated
Pairs or groups perform the experiment in front of others or present the outcome of the experiment they performed at home

To check the efficacy of the each experiment

To discuss the effects of the experiments

Goods for the experiments

Digital camera

Following the performance

Discussion

$45 \mathrm{~min}$

\subsection{Activity 7 - [II. Famous scientists]: the research assignment}

The assignment is presented on a session in a classroom.

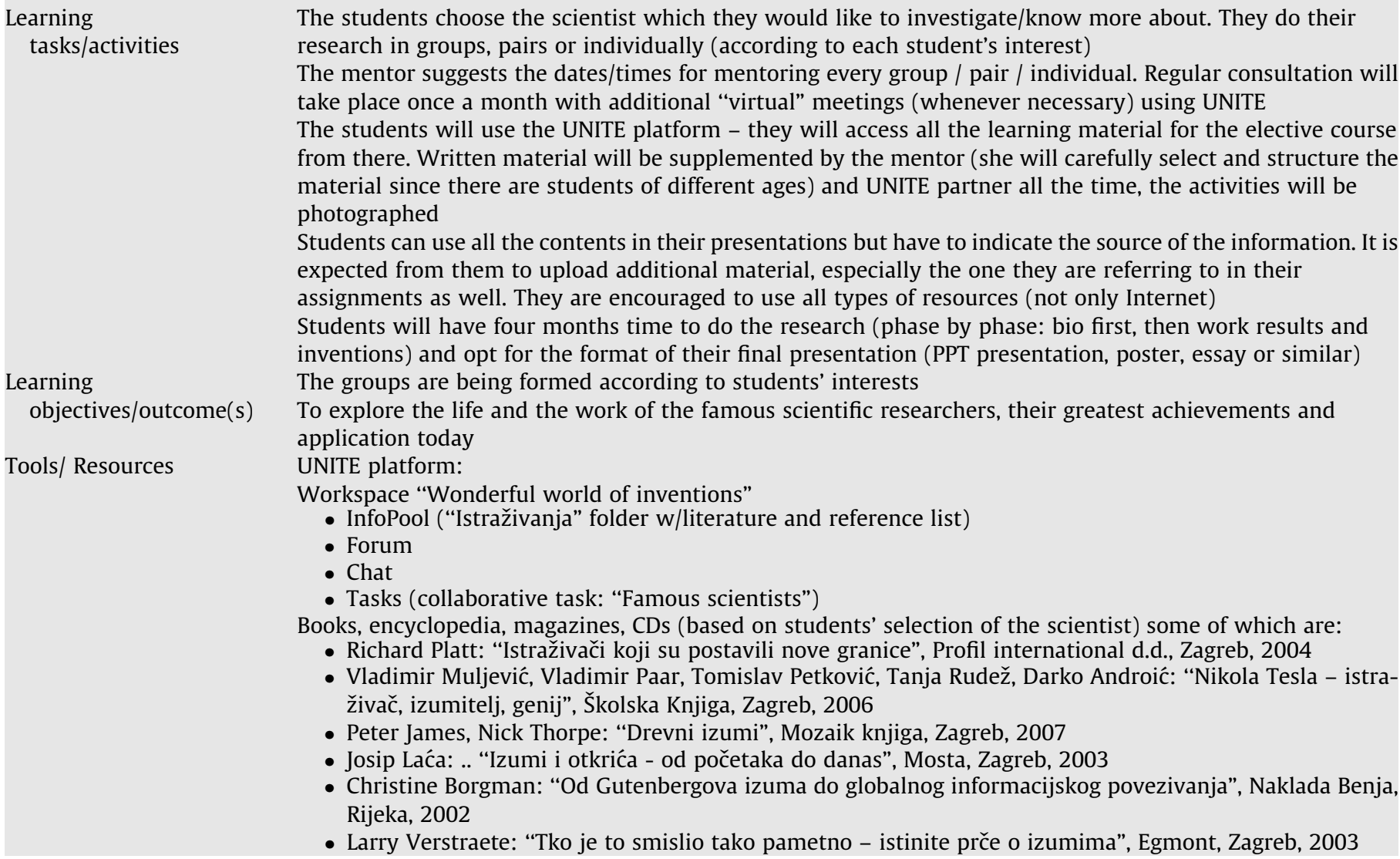




$\begin{array}{ll}\begin{array}{l}\text { Assessment strategy } \\ \text { (feedback and/or }\end{array} & \begin{array}{l}\text { Tracking and monitoring students' work on the assignment } \\ \text { evidence) }\end{array} \\ & \begin{array}{l}\text { Consultations } \\ \text { Insight into students' notes }\end{array} \\ \text { Discussion } \\ \text { Time allocated }\end{array}$

\subsection{Activity 8 - introducing mediaBoard}

The mediaBoard is presented in a classroom.

Learning tasks/activities

Learning objectives/outcome(s) Tools/resources

Assessment strategy (feedback and/or evidence)

Time allocated

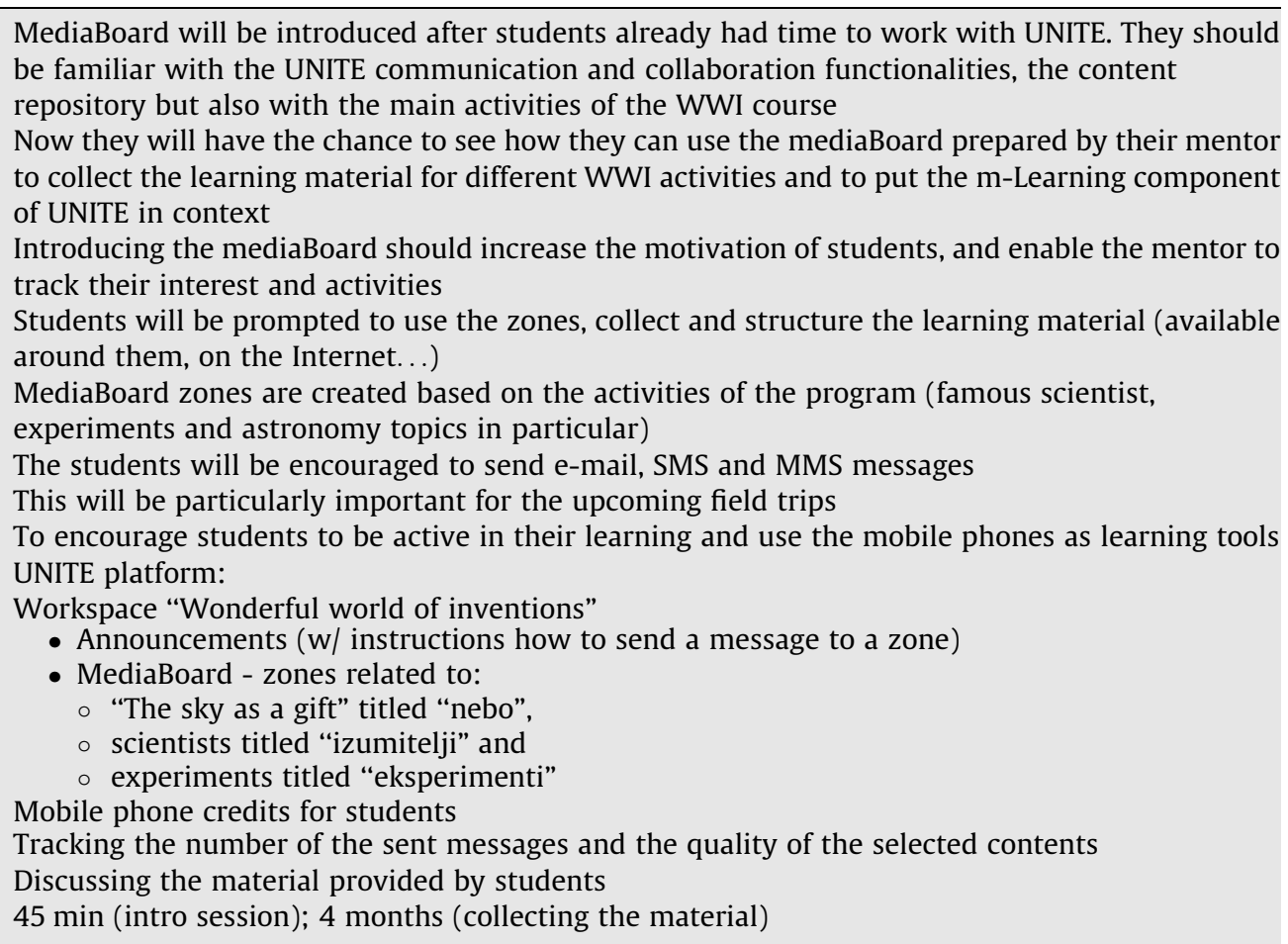
be familiar with the UNITE communication and collaboration functionalities, the content repository but also with the main activities of the WWI course of UNITE in context

Introducing the mediaBoard should increase the motivation of students, and enable the mentor to track their interest and activities around them, on the Internet...

MediaBoard zones are created based on the activities of the program (famous scientist, experiments and astronomy topics in particular)

e students will be encouraged to send e-mail,

To encourage students to be active in their learning and use the mobile phones as learning tools UNITE platform:

orkspace "Wonderful world of inventions"

- MediaBoard - zones related to:

- "The sky as a gift" titled "nebo",

- scientists titled "izumitelji" and

- experiments titled "eksperimenti"

Mobile phone credits for students

Discussing the material provided by students

45 min (intro session); 4 months (collecting the material)

3.9. Activity 9 - [II. Famous scientists]: the field trip to technical museum in Zagreb

Learning activities take place on a one-day trip to Zagreb.

\begin{tabular}{|c|c|}
\hline Learning tasks/activities & $\begin{array}{l}\text { A one-day visit to the Technical museum in Zagreb (http://www.mdc.hr/tehnicki/en) will be organized. In } \\
\text { particular, the relation to students' research of famous scientist should be made clear: permanent } \\
\text { exhibition of Nikola Tesla is the main motive of the excursion } \\
\text { The in situ learning is planned ahead. Students are given clear assignments (what can they see, what can } \\
\text { expect and what is expected from them). Roles and individual responsibilities are agreed. Students' } \\
\text { expectations, and their responsibilities will be discussed before the visit mostly using the UNITE platform } \\
\text { (chat, messages and forum). Students look at the museum's website and they share their experiences (in } \\
\text { case someone has been there already). Mentor will also talk to students during the four-hour trip about } \\
\text { the highlights of the exhibition and Tesla's achievements } \\
\text { Students will be taking observation notes and recording media }\end{array}$ \\
\hline $\begin{array}{l}\text { Learning objectives/ } \\
\text { outcome(s) }\end{array}$ & $\begin{array}{l}\text { To expand the knowledge about technical achievements } \\
\text { To find out more about Nikola Tesla } \\
\text { To provide a framework (structure) for the research assignment }\end{array}$ \\
\hline Tools/ Resources & $\begin{array}{l}\text { Digital camera } \\
\text { Mobile phones } \\
\text { Digital camcorder } \\
\text { UNITE platform: } \\
\text { - Workspace "Wonderful world of inventions" } \\
\text { - MediaBoard zones } \\
\text { - Chat } \\
\text { - Messages } \\
\text { - Forum }\end{array}$ \\
\hline $\begin{array}{l}\text { Assessment strategy } \\
\text { (feedback and/or evidence) }\end{array}$ & $\begin{array}{l}\text { Discussion } \\
\text { Insight into students' notes and into collected online and offline information }\end{array}$ \\
\hline Time allocated & 1 day \\
\hline
\end{tabular}


3.10. Activity 10 - [II. Famous scientists]: the students' presentations

The presentations are given in a classroom.

\begin{tabular}{|c|c|}
\hline Learning tasks/activities & $\begin{array}{l}\text { The students choose the way of presenting their results (PowerPoint presentation placed in the } \\
\text { UNIITE platform, poster pictures, and essay) } \\
\text { They present their work within a given timeframe (around } 20-30 \text { min per group) }\end{array}$ \\
\hline \multirow[t]{3}{*}{ Learning objectives/outcome(s) } & To present own work in front of the class \\
\hline & $\begin{array}{l}\text { To get an insight into the acquired information, ability to navigate on the Internet (the skill of } \\
\text { "filtering" information) }\end{array}$ \\
\hline & The skill of making a PPT presentation or some other product \\
\hline \multirow[t]{3}{*}{ Tools/resources } & LCD projector \\
\hline & Computer \\
\hline & $\begin{array}{l}\text { UNITE platform: } \\
\text { - Workspace "Wonderful world of inventions" } \\
\text { - My InfoPool of the student presenting } \\
\text { - Trace viewer }\end{array}$ \\
\hline \multirow[t]{3}{*}{$\begin{array}{l}\text { Assessment strategy (feedback } \\
\text { and/or evidence) }\end{array}$} & $\begin{array}{l}\text { Validation/assessment of the work (all the participants - other groups and the mentor, associates, log } \\
\text { files...) }\end{array}$ \\
\hline & Self assessment \\
\hline & Discussion \\
\hline Time allocated & $3 \times 45 \min$ \\
\hline
\end{tabular}

\subsection{Activity 11 - organized discussion about the content/activities of the course}

Discussion is supported by UNITE communication tools and takes place on the Internet.

\begin{tabular}{ll}
\hline Learning tasks/activities & $\begin{array}{l}\text { Students are encouraged to participate in UNITE forum and chat discussions related to the activities of WWI } \\
\text { They choose one or more topics for discussion. Discussion threads are decided by students and the } \\
\text { mentor. Mentor starts the topic and encourages students to suggest more topics in order to find the } \\
\text { subject of interest } \\
\text { To extend understanding of selected discussion topic and to motivate students for additional } \\
\text { research of the subject } \\
\text { To express own opinion and argument it; to respect other people's opinions } \\
\text { To develop netiquette of forum posts } \\
\text { Computer } \\
\text { UNITE platform: } \\
\text { - Workspace "Wonderful world of inventions" } \\
\text { - Forum (topics related to WWI course) }\end{array}$ \\
$\begin{array}{ll}\text { Tools/resources } \\
\text { Individual evaluation of student's efforts and contributions to discussion } \\
\text { and/or evidence) }\end{array}$ \\
$\begin{array}{ll}\text { Time allocated } & \text { Throughout the whole school year }\end{array}$ \\
\hline
\end{tabular}

\subsection{Activity 12 - [III. Scientific method]: introducing the scientific research}

Three intro sessions will be organized in a classroom.

Learning tasks/activities
In three separate sessions students will find out more about the theory of scientific research from their teacher and will practice the routine. Every session has its own topic:

- Be introduced to the scientific "protocol" or the phases of the scientific research

- Introduction is followed by individual exercises and theory basics (e.g. individual tracking of changes on samples, taking notes, using a microscope)

- Then, students will find out how to use and prepare their Science portfolio/their notes

The purpose of these activities is to prepare students for the field trip to MedILS lab (not accessible to wider public). Students are given clear instructions (what can they see, what can expect and what is expected from them). Additional preparation for the visit can be done online, using UNITE (forum and messages), where pupils can prepare questions for the scientists. Mentor tracks the log using Trace viewer as a part of his assessment strategy

Students will be taking observation notes in the laboratory where a molecular biologist will do some experiments with students (according to her/his preference). Students will not be prescribed/imposed what to write down. Instead, they will write down what they saw, how they felt, is there a pattern they witnessed etc. 


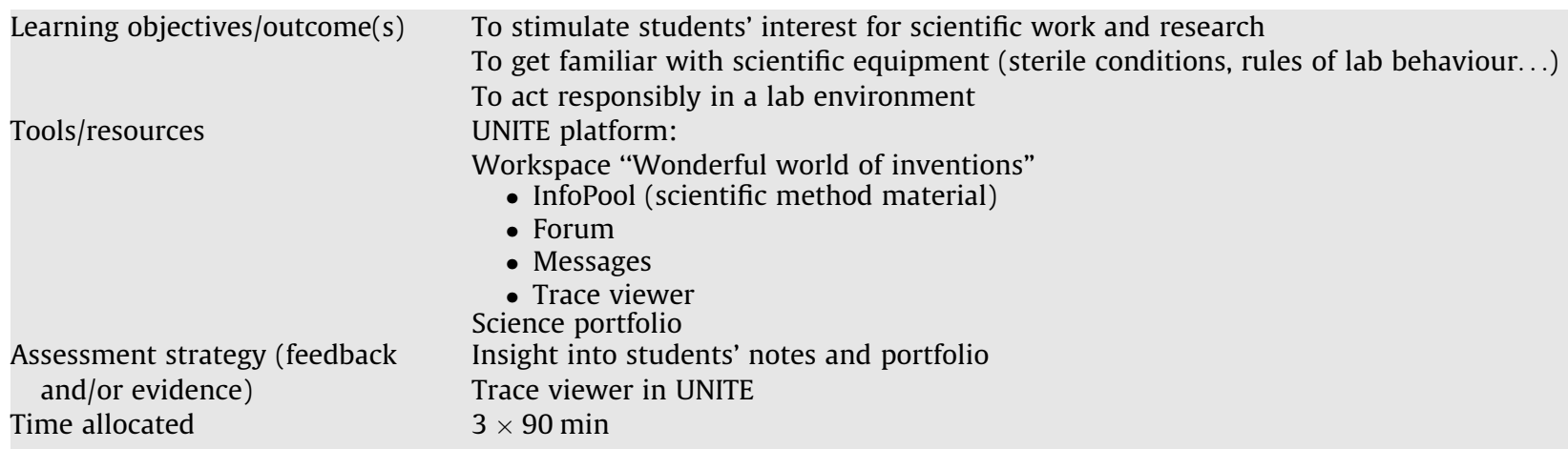

Time allocated

\subsection{Activity 13 - [III. Scientific method]: visit to MedILS laboratories}

Learning activities take place in Mediterranean Institute for Life Sciences (MedILS) labs.

\begin{tabular}{|c|c|}
\hline Learning tasks/activities & $\begin{array}{l}\text { Up to three visits (depending on lab availability) to Mediterranean Institute for Life Sciences } \\
\text { (MedILS; http://www.medils.hr/eng) are organized. MedILS is an international "renaissance" project, } \\
\text { somewhat inspired by the Florence Academy of Medici, and set up as a scientific, social and even } \\
\text { political experiment. Its primary goal is to breed a specially trained generation of young scientists: } \\
\text { creative, multidisciplinary professionals trained to think the unthinkable and do experiments about } \\
\text { it } \\
\text { Students will meet the scientists, talk to them, see the lab equipment, do several experiments with } \\
\text { one of the biologists etc. } \\
\text { They will take written and multimedia "notes" (images, videos, audio files), recordings (sent to } \\
\text { UNITE mediaBoard) }\end{array}$ \\
\hline Learning objectives/outcome(s) & $\begin{array}{l}\text { To act responsibly in a lab environment } \\
\text { To recognize the scientific "pattern" }\end{array}$ \\
\hline Tools/resources & $\begin{array}{l}\text { Digital camera } \\
\text { Mobile phones } \\
\text { Digital camcorder } \\
\text { UNITE platform: "Wonderful world of inventions" } \\
\text { - Workspace "Wones } \\
\text { - MediaBoard zones } \\
\text { Science portfolio }\end{array}$ \\
\hline $\begin{array}{l}\text { Assessment strategy (feedback and/ } \\
\text { or evidence) }\end{array}$ & Insight into students' notes and portfolio \\
\hline Time allocated & $3 \times 60 \mathrm{~min}$ \\
\hline
\end{tabular}

\subsection{Activity 14 - [IV. The sky as a gift]: introducing the project}

The intro activities are organized in a classroom.

Learning tasks/activities

Learning objectives/outcome(s)

Tools/resources

Assessment strategy (feedback and/or evidence)

Time allocated
Students are introduced to astronomy basics and are given notebooks provided by the project "The sky as a gift" (http://nebo.znanost.org) from Croatian Physics Society The notebooks contain step-by-step instructions and 10 different astronomy exercises for observing changes in the sky (to be exercised individually). Since these notebooks are provided by the project and is expected from students to observe and write down their remarks, UNITE will be used to facilitate knowledge sharing and as a place to write down their reflections (forum, InfoPool, messages)

To engage students in learning astronomy

To learn the basic astrology terms

Telescope

"The sky as a gift" notebook

$\mathrm{CD}$ (sky maps for the whole year)

UNITE platform:

- Workspace "Wonderful world of inventions"

- Forum

- InfoPool

- Mesasges

Informal feedback

45 min 
3.15. Activity 15 - [IV. The sky as a gift]: individual exercises for students

The sky observation takes place at home.

\begin{tabular}{|c|c|}
\hline Learning tasks/activities & $\begin{array}{l}\text { Students have to complete the } 10 \text { forms in the notebook. There are } 10 \text { individual exercises of sky } \\
\text { observation with step-by-step instructions. Every exercise lasts for about } 1,5 \text { hour. Students } \\
\text { communicate via UNITE platform among themselves and with the mentor. Each exercise contains } \\
\text { about } 10 \text { open-ended questions where student is supposed to write down what she/he has seen that } \\
\text { night on the sky. }\end{array}$ \\
\hline \multirow[t]{3}{*}{ Learning objectives/outcome(s) } & To learn how to "read" the sky map \\
\hline & To find some planets and planet mists \\
\hline & To learn basic astrology terms \\
\hline \multirow[t]{4}{*}{ Tools/resources } & Telescope \\
\hline & "The sky as a gift" notebook \\
\hline & CD (sky maps for the whole year) \\
\hline & $\begin{array}{l}\text { UNITE platform: } \\
\text { - Workspace "Wonderful world of inventions" } \\
\text { - Forum } \\
\text { - Chat } \\
\text { - Messages } \\
\text { - mediaBoard zone }\end{array}$ \\
\hline Assessment strategy (feedback & Insight into students' notebooks \\
\hline and/or evidence) & Tracking Forum and Chat discussions \\
\hline Time allocated & $10 \times 90 \mathrm{~min}$ \\
\hline
\end{tabular}

\subsection{Activity 16 - [IV. The sky as a gift]: visit to Astro Village Mosor}

Learning activities take place during an overnight stay to Astro Village Mosor.

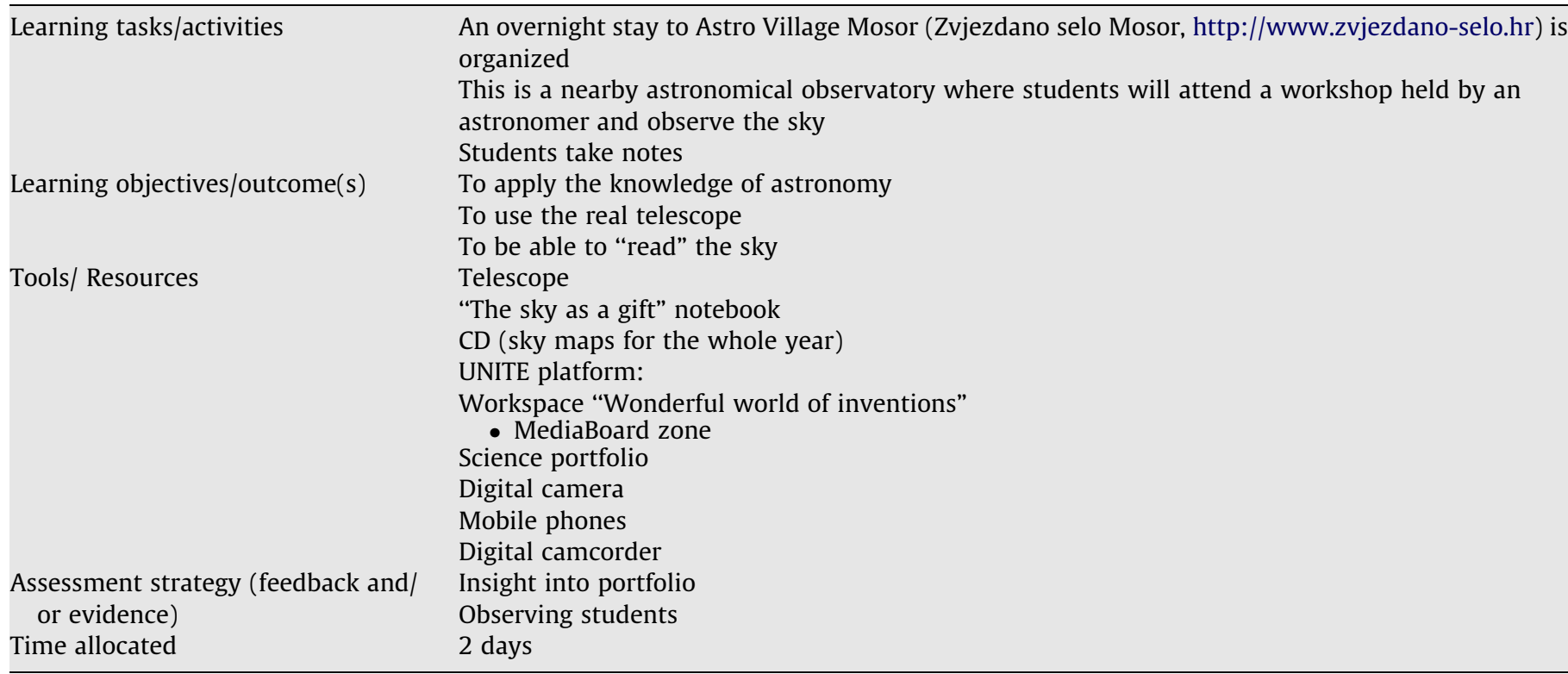

\subsection{Activity 17 - prototyping}

The learning activities take place in the Technical education classroom. topics: airplane, parachute, incredible machine...

Students can choose one of the suggested projects or to opt for their own

On their first session students opt for a project and list down the things they would need with the mentor

Second session is reserved for creating sketches and based on the sketch students build a model/a prototype on the third 90-min session 
Learning objectives/outcome(s)

Tools/resources

Assessment strategy (feedback and/or evidence)

Time allocated
To deepen the interest of students and to encourage the creativity and creation To build a sketch and a model

To gain practical skills

To promote the fiction, fluency of idea and originality

Various tools for model building

Drawing material

Books (e.g. Gorg Blanc: “Papir za modeliranje - ručni radovi za djecu”, Neretva, Zagreb, 2004.)

Technical manuals

Digital camera

Consultations

Observation

$3 \times 90 \mathrm{~min}$

\subsection{Activity 18 - exercises for senses and promoting creativity}

The learning activities take place in a classroom.

\begin{tabular}{ll}
\hline Learning tasks/activities & Practicing the senses and promoting creativity (e.g. observing and taking notes about an apple, \\
& bubble gum experiment etc.) \\
& Various hypotheses will be set and investigated during 5 sessions \\
& E.g. one session could happen like in the following \\
& Up to five different trade marks of bubble-gums are presented to students. They set several \\
& hypotheses related to which bubble-gum produces the largest bubble and why. The experimenter \\
& then chews the first bubble-gum and after a set period of time, s/he blows a bubble. The bubble is \\
then measured, and the measures are written down. Once all the bubbles are blown and all the & measures are written down students compare the results with their hypotheses. They conclude and \\
& present their results using graphs and descriptive statistics (with the help from the mentor) \\
& UNITE InfoPool will be used to store the results and pictures from the sessions \\
& To encourage creativity, fluency of ideas and originality. \\
& Structured notes \\
Learning objectives/ outcome(s) & Science portfolio \\
Tools/ Resources & UNITE platform: "Workspace "Wonderful world of inventions" \\
& • My InfoPool \\
Assessment strategy (feedback & Reading notes \\
and/or evidence) & Self assessment \\
& Discussion \\
Time allocated & $5 \times 45$ min \\
\hline
\end{tabular}

\subsection{Activity 19 - robotics workshop}

The learning activities take place at Faculty of Electrical Engineering, Mechanical Engineering and Naval Architecture.

Learning tasks/activities

Learning objectives/outcome(s)

Tools/resources

Assessment strategy (feedback and/or evidence)

Time allocated
Two robotics workshops will be organized at Faculty of Electrical Engineering, Mechanical Engineering and Naval Architecture (in cooperation with Faculty staff). Students will put together a small robot using a FISHER robot kit. The professor of robotics from the Faculty will introduce the students to robots in general $(20 \mathrm{~min})$, s/he will provide examples where we use robots and why? How do students imagine robots? Then groups of students ( 2 to 3 of them, students form groups themselves) put together a "car" robot or a "bug" robot using LEGOs until the end of the first session Second session is reserved for "connecting" robots with the computer (using InfraRed) and loading the specific program. There could be a discussion related to programming of robots as well Pictures and video will be taken and uploaded to MediaBoard

To adopt terms related to robotics

To gain practical skills and to understand the working principles of a robot Robot kit Science portfolio UNITE platform:

- Workspace "Wonderful world of inventions"

- mediaBoard zone

Digital camera

Informal observation insight into portfolio

Personal students' impressions

$2 \times 90 \mathrm{~min}$ 


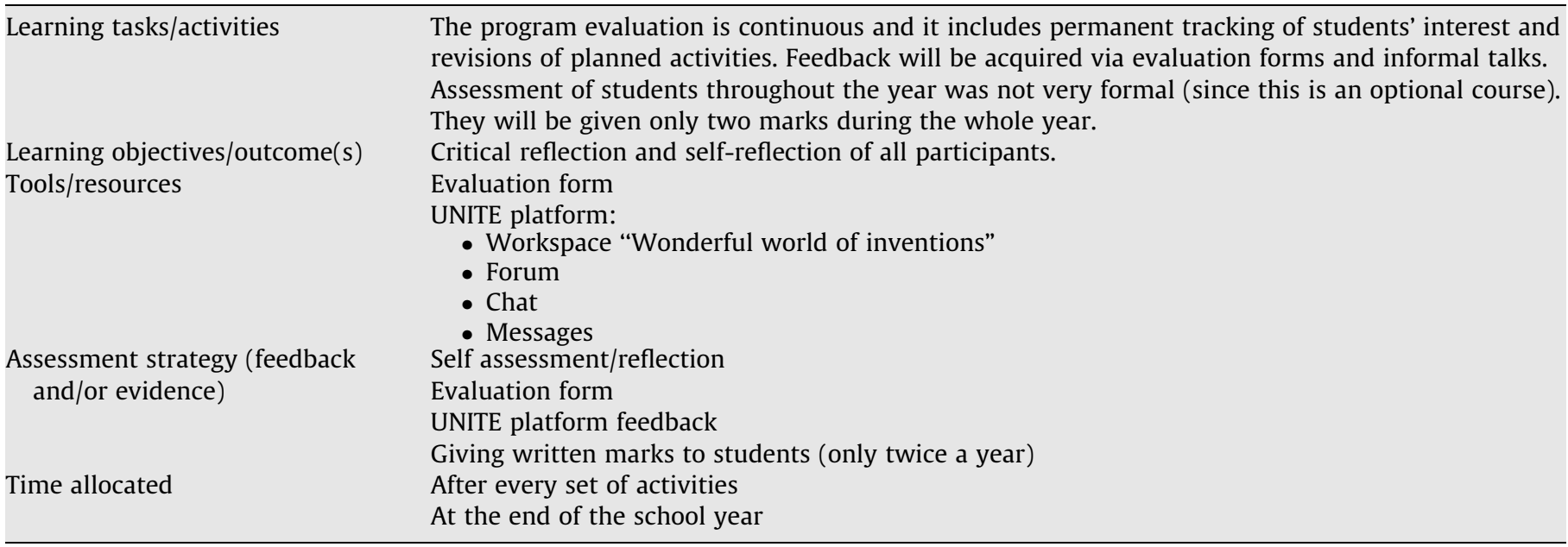

\subsection{Activity 21 - WWI exhibition/presentation}

\begin{tabular}{ll}
\hline Learning tasks/activities & $\begin{array}{l}\text { Photos, works and other most interesting artefacts from WWI sessions will be exhibited in the } \\
\text { school's atrium (including screenshots from the platform and MediaBoard zone contents) } \\
\text { To present to parents, school's staff, students and Faculty employees the activities conducted } \\
\text { throughout the year } \\
\text { To animate other students and associates to participate in the project } \\
\text { Photos and various artefacts from all the program phases } \\
\text { Digital camera }\end{array}$ \\
$\begin{array}{ll}\text { Tools/resources } \\
\begin{array}{l}\text { Assessment strategy (feedback } \\
\text { and/or evidence) }\end{array}\end{array}$ & $\begin{array}{l}\text { Book of impressions } \\
\text { Time allocated }\end{array}$
\end{tabular}

\section{References}

Alessi, S. M., \& Trollip, R. S. (2001). Multimedia for learning. methods and development. Boston, Allyn and Bacon (cited in Ćukušić et al. (2006)).

Atkinson, T. (Ed.). (2001). Reflections on ICT. London: CILT.

Beetham, H. (2004). Draft template for describing a unit of (e)learning. In Designing for Learning theme of the e-Learning and Pedagogy programme of Joint Information Systems Committee (JISC).

Black, P., \& Wiliam, D. (1998). Assessment and classroom learning. Assessment Education: Principles, Policy and Practice, 5(1), 7-74. In Roos, B. (2002). ICT, Assessment and the Learning Society. Conference of the European Educational Research Association. Lisbon, September, 2002.

Boer, W., \& Collis, B. (2002). A changing pedagogy in E-learning: From acquisition to contribution. Journal of Computing in Higher Education, 13(2), 87-101. doi:10.1007/ BF02940967.

Bradley, C., \& Oliver, M. (2002). The evolution of pedagogic models for work-based learning within a virtual university. Computers and Education, 38, 37-52.

Cartwright, V., \& Hammond, M. (2007). Fitting it in: A study exploring ICT use in a UK primary school. Australasian Journal of Educational Technology, $23(3), 390-407$.

Conole, G., \& Oliver, M. (1998). A pedagogical framework for embedding C\&IT into the curriculum. ALT-J, 6(2), 4-16.

Cukušić, M., Granić, A., Mifsud, C., \& Zammit, M. (2008). Deliverable D4.3: Pedagogical framework implementation report (final). UNITE report. Retrieved October 16, 2008. Available from: <www.unite-ist.org>.

Ćukušić, M., Granić, A., Pagden, A., Walker, R., \& Zammit, M. (2006). UNITE deliverable D4.1: UNITE Pedagogical Framework Design.

Ćukušić, M., MacRae, N., Zammit, M., Kellner, A., Pagden, A., Nikolova, N. et al. (2007). Deliverable D4.2: Pedagogical framework implementation report on UNITE-V1; UNITE teachers' handbook. UNITE report. Retrieved October 16, 2008. Available from: <www.unite-ist.org>.

Dimitrova, M., Mimirinis, M., \& Murphy, A. (2004). Evaluating the flexibility of a pedagogical framework for e-Learning. In Proceedings of the IEEE international conference on advanced learning technologies, ICALT (pp. 291-295). Washington, DC: IEEE Computer Society.

Downes, T., Fluck, A. Gibbons, P., Leonard, R., Matthews, C., \& Oliver, R. (2001). Making better connections. models of teacher professional development for the integration of ICT into classroom practice. A Report to the Commonwealth Department of Education, Science and Training, Commonwealth of Australia, Canberra.

Earle, A. (2002). Designing for pedagogical flexibility - Experiences from the CANDLE project. Journal of Interactive Media in Education, 4.

Goodyear, P. (1999). Pedagogical frameworks and action research in open and distance learning. European Iournal of Open and Distance Learning, June 1999. Retrieved October 7, 2008. Available from: <http://www.eurodl.org/materials/contrib/1999/goodyear/>.

Granić, A., \& Cukušić, M. (2007a). Universal design within the context of e-Learning. Lecture Notes in Computer Science, 4556, 617-662.

Granić, A., \& Ćukušić, M. (2007b). An Approach to the Design of Pedagogical Framework for e-Learning. In CD proceedings of EUROCON 2007, computer as a tool (pp. 24152422). Warsaw, Poland.

Gray, A. (1997). Contructivist teaching and learning. SSTA Research Centre Report \#97-07.

Greene, M. (1979). Teaching: the question of personal reality. In A. Liebermann \& L. Miller (Eds.), Staff development: New demands, new realities, new perspectives (pp. 23-35). New York: Teachers College, Columbia University.

Grégoire, R., Bracewell, R., \& Lafferière, T. (1996). The contribution of new technologies to learning and teaching in elementary and secondary schools: Documentary review. Ottawa: SchoolNet. Retrieved October 15, 2008. Available from: <http://www.fse.ulaval.ca/fac/tact/fr/html/impactnt.html>.

Grogan, G. (2005). The design of online discussions to achieve good learning results. Retrieved October 16, 2008. Available from: <www.eLearningeuropa.info>.

Groundwater Smith, S., \& Walker, R. (2000). Case study and case records: A conversation about the Hathaway project. In H. Altrichter \& J. Elliott (Eds.), Images of educational change (pp. 136-146). Buckingham, Philadelphia: Oxford University Press. 
Hanson-Smith, E. (2000). The role of technological environments in language education. In E. Hanson-Smith (Ed.), Technology-enhanced learning environments (pp. 1-3). Virginia: TESOL, Inc.

Harrison, C., Comber, C., Fisher, T., Haw, K., Lewin, C., \& Lunzer, E. (2002). ImpaCT2: The impact of information and communication technologies on pupil learning and attainment. Annersley, Notts, UK: DfES.

Hayes, D. N. (2007). ICT and learning: Lessons from Australian classrooms. Computers and Education, 49(2), 385-395. doi:10.1016/j.compedu.2005.09.003. Scopu.

Haymore Sandholtz, J., Ringstaff, C., \& Dwyer, D. C. (1997). Teaching with technology - creating student-centred classrooms. New York: Teachers College, Columbia University.

Hayward, B., Alty, C., Pearson, S., \& Martin, C. (2003). Young people and ICT 2002: Findings from a survey conducted in autumn 2002. Coventry: British Educational Communications and Technology Agency. Retrieved October 16, 2008. Available from <www.becta.org.uk/research>.

Haywood, J. (2005). eLearning strategy for the university. University of Edinburgh. Retrieved October 16, 2008. Available from: <www.elearn.malts.ed.ac.uk/issues/news/ ebreaks0506/downloads/jhaywoodpres.pdf>.

Healey, D. (1999). Theory and research: Autonomy in language learning. In J. Egbert \& E. Hanson-Smith (Eds.), CALL environments: Research, practice, and critical issues (pp. 391-402). Alexandria, VA: Teachers of English to Speakers of Other Languages, Inc.

Hewer, S., \& Shield, L. (2001). Online communities: Interactive oral work at a distance. In T. Atkinson (Ed.), Reflections on ICT. London: CILT.

Hoffman, B., \& Ritchie, D. C. (1998). Teaching and learning online: Tools, templates, and training. In Proceedings of SITE 1998 (Society for Information Technology and Teacher Education). Charlottesville, VA: CD-ROM edition, Association for the Advancement of Computing in Education.

Holec, H. (Ed.). (1988). Autonomy - Self-directed learning: Present fields of application. Strasbourg: Council of Europe.

Hornung, Ch., Granić, A., Ćukušić, M., \& Nazemi, K. (2008). eKnowledge Repositories in eLearning 2.0: UNITE - A European-wide network of schools. In F. Li et al. (Eds.), ICWL 2008, LNCS 5145 (pp. 99-110). Berlin Heidelberg: Springer-Verlag.

Iliev, T., Gachev, G., \& Nikolova, I. (2007). Data driven user requirements specification in the UNITE project. In Book of Abstracts, International Conference Pioneers of the Bulgarian Mathematics (pp. 56-57).

Jonassen, D. (1996). Computers in the classroom: Mindtools for critical thinking. Englewood Cliffs, New Jersey: Merrill, Prentice Hall.

Kannan, R., \& Bento, A.M. (1996). A Learning Centred Approach to Education using Hypermedia and the Internet. Retrieved May 12, 2009 , from http://home.ubalt.edu/abento/ ais/teach96h.html.

Kellner, A., Teichert, V., Hagemann, M., Ćukušić, M., Granić, A., Pagden, A., et al. (2008). Deliverable D7.2: Report of validation results. UNITE report. Retrieved May 11, 2009. Available from: <www.unite-ist.org>.

Kohn, K. (2005). eLearning for languages. Technological solutions and pedagogic opportunities. Leonardo da Vinci, Contact Seminar.

Kouloumbis, A., Lu, Y., \& Wunner, R. (2007). Deliverable D3.1: UNITE V1 platform. Short introduction of the platform and its main components. UNITE report. Retrieved October 16, 2008. Available from <www.unite-ist.org $>$.

Kynigos, C. (1995). We should not miss the chance: Educational technology as a means expression and observation in general education. In A. Kazamias, M. Kasotakis (Eds.), Greek education, perspectives of reformulation and modernization (pp. 396-416).

Lehofer, W. (2005). eLearning in the eEurope policy framework. In ASEM, 4th conference on eCommerce. London.

Leonard, C. (2003). Pedagogical principles: Paradigms, or Platitudes. In D. Lassner, C. McNaught (Eds.), Proceedings of world conference on educational multimedia, hypermedia and telecommunications (pp. 2142-2143). Chesapeake, VA: AACE.

Lim, G. (2001). A framework for integrating technologies in teaching and learning. In C. Crawford et al. (Eds.), Proceedings of society for information technology and teacher education international conference 2001 (pp. 2751-2756). Chesapeake, VA: AACE.

Limanauskiene,V., Stuikys, V., \& Sitikovs, V. (2008). Deliverable D6.2: Content-enriched network of schools installed. UNITE report. Retrieved October 16, 2008. Available from: $<$ www.unite-ist.org>.

Little, D. (1991). Learner autonomy 1: Definitions, issues and problems. Dublin: Authentik Language Learning Resources Ltd.

Loveless, A. M. (2002). Literature review in creativity, new technologies, and learning. (Report No. 4). Bristol, UK: NESTA Futurelab. Retrieved October 15, 2008. Available from: <http://www.futurelab.org.uk/resources/documents/lit_reviews/Creativity_Review.pdf>.

Lu, Y., Bhatti, N., Godehardt, E., Samara, V., Doskas, K., Kouloumbis, A. et al. (2006). Deliverable D2: UNITE system design. UNITE report. Retrieved October 16, 2008. Available from: <www.unite-ist.org>.

Mällinen, S. (2001). Teacher effectiveness and online learning. In J. Stephenson (Ed.), Teaching and learning online: Pedagogies for new technologies. London: Kogan Page Ltd.

Mansberger, R., Bauer, T., \& Heine, E. (2006). FLOP or TOP: Experiences with eLearning in academic education. FIG-WORKSHOP Budapest.

Marcelo, C. (2006). Ask whatever you like. Teacher-pupil interaction in new virtual learning environments. Retrieved October 16, 2008. Available from: $<$ www.eLearningeuropa.info>.

Mason, R. (2002). Review of e-Learning for education and training. In S. Banks, P. Goodyear, V. Hodgson, D. McConnell (Eds.), Networked learning 2002. A research based conference on e-Learning in higher education and lifelong learning. UK: Lancaster University and University of Sheffield.

Mayes, T. (2001). Learning technology and learning relationships. In Teaching and learning online: Pedagogies for new technologies. London: Kogan Page Ltd.

McConnell, D. (2000). Implementing computer supported cooperative learning. London: Kogan Page.

McConnell, D. (2006). e-Learning groups and communities: Imagining learning in the age of the internet. OU Press.

Meredyth, D., Russell, N., Blackwood, L., Thomas, J., \& Wise, P. (1999). Real time: Computers, change and schooling. National sample study of the information technology skills of Australian students. Canberra: Department of Education, Training and Youth Affairs.

Mödritscher, F., Spiel, S., \& Garcia-Barrios, V. (2006). Assessment in e-Learning environments: A comparison of three methods. In C. Crawford et al. (Eds.), Proceedings of society for information technology and teacher education international conference (pp. 108-113).

Passey, D., Rogers, C., Machell, J., \& McHugh, G. (2004). The motivational effect of ICT on pupils. Report No: RR523. England:DfES/University of Lancaster. Retrieved October 16, 2008. Available from <http://www.dfes.gov.uk/research/data/uploadfiles/RR523new.pdf>.

Prince, M. (2004). Does active learning work? A review of the research. Journal of Engineering Education, 93(3), 1-10.

Quinton, S., Dreher, H., Fisher, D., \& Houghton, P. (2005). Harnessing technology to empower mature age learners. In D. Fisher, D. Zandvliet, I. Gaynor, \& R. Koul (Eds.), Fourth international conference on science, mathematics and technology education (pp. 490-499). Victoria, British Columbia, Canada: Curtin University of Technology.

Reeves, T. C. (1994). Evaluating what really matters in computer-based education. In M. Wild \& D. Kirkpatrick (Eds.), Computer education: New perspectives (pp. 219-246). Perth, Australia: MASTEC

Sanchez, J., \& Salinas, A. (2008). ICT and learning in Chilean schools: Lessons learned. Computer and Education, 51(4), 1621-1633. doi:10.1016/i.compedu.2008.04.001.

Sharma, R., \& Mishra, S. (2007). Global e-learning practices: An introduction. In R. Sharma \& S. Mishra (Eds.), Global cases in e-Learning practices: Successes and pitfalls (pp. 1-11). Hearsey: IDEA Group Publishing.

Sime, D., \& Priestley, M. (2005). Student teachers' first reflections on ICT in classroom learning: Implications for initial teacher education. Journal of Computer Assisted Learning, 21(2), 130-143.

Sivan, A., Wong Leung, R., \& Woon, C. (2000). An implementation of active learning and its effect on the quality of student learning. Innovations in Education and Training International, 37(4), 381-389. Scopus.

Tzanavari, A. (2007). Deliverable D5.2: 1st version of specific UNITE eLearning Scenarios: Part II: Handbook for content development v.2. UNITE report. Retrieved October 16, 2008. Available from <www.unite-ist.org>.

Ullrich, C., Borau, K., Luo, H., Tan, X., Shen, L., \& Shen, R. (2008). Why Web 2.0 is good for learning and for research: Principles and prototypes. In 17 th conference WWW 2008 (pp. 705-714). April 21-25, 2008. Beijing, China.

Ullrich, K. (2004). Constructivism and the 5 E model science lesson. Retrieved October 16, 2008. Available from: <http://cte.jhu.edu/techacademy/fellows/Ullrich/webquest/ mkuindex.html>.

UNITE deliverable D1 (2006). State of the art and requirement list for UNITE.

UNITE FP6 IST project (2006). Contract No. 026964. Website: <http://www.unite-ist.org>.

Volery, T., \& Lord, D. (2000). Critical success factors in online education. International Journal of Educational Management, 14(5), 216-223.

Walker, R. (2002). Case study, case records and multimedia. Cambridge Journal of Education, 32(1), 109-127.

Warschauer, M., Shetzer, H., \& Meloni, C. (2000). Internet for English teaching. Virginia: TESOL, Inc.

Yoder, J. D., \& Hochevar, C. M. (2005). Encouraging active learning can improve students, performance on examinations. Teaching of Psychology, 32(2), 91-95. Scopus.

Zoakou, A., Tzanavari, A., Papadopoulos, G. A., \& Sotiriou, S. (2007). A methodology for eLearning scenario development: The UNITE approach. In Proceedings of the ECEL2007 -

Zuropean conference on e-Learning (pp. 683-692). Copenhagen, Denmark: ACL publications. report. Retrieved October 16, 2008. Available from: <www.unite-ist.org>. 